\title{
Current and Future Treatments for Graves' Disease and Graves' Ophthalmopathy
}

Authors

Anupam Kotwal, Marius Stan

\author{
Affiliation \\ Division of Endocrinology, Diabetes, Metabolism, and \\ Nutrition, Mayo Clinic, MN, USA \\ Key words \\ autoimmunity, thyroid function, hyperthyroidism, \\ immunotherapy \\ received 02.05 .2018 \\ accepted 03.09.2018 \\ Bibliography \\ DOI https://doi.org/10.1055/a-0739-8134 \\ Published online: 4.10.2018 \\ Horm Metab Res 2018; 50: 871-886 \\ (c) Georg Thieme Verlag KG Stuttgart · New York \\ ISSN 0018-5043 \\ Correspondence \\ Marius Stan, MD \\ Associate Professor of Medicine \\ Division of Endocrinology \\ Diabetes, Metabolism, and Nutrition \\ Mayo Clinic \\ 200 First Street SW \\ Rochester \\ $55905 \mathrm{MN}$ \\ USA \\ Tel.: + 1/507/284 2463, Fax: +1/507/284 5745 \\ Stan.Marius@mayo.edu
}

\begin{abstract}
The course and pathogenesis of Graves' disease and Graves' ophthalmopathy are interdependent, influencing each other's therapeutic choices. Multiple factors including geographic location, access to medical services, patient and physician preferences influence the management of these conditions. Graves' disease is classically managed with one of three treatment options - antithyroid drugs, radioactive iodine, and thyroidectomy. In recent years, there has been a shift towards antithyroid drugs, including long term therapy with these agents, given the advantage of avoiding hypothyroidism and the apparent safety of this approach. In addition, new therapies are (slowly) emerging, focusing on immunomodulation. Technological advances are opening doors to non-pharmaceutical interventions that aim to deal with both structural thyroid abnormalities as well as biochemical abnormalities of hyperthyroidism. Graves' ophthalmopathy management is guided by its activity and severity status, with treatment options including smoking cessation, control of hyperthyroidism, local eye measures, glucocorticoids, selenium, orbital radiotherapy, and surgery. In addition to these established treatment choices, new immunotherapy-based approaches are being tested. Some of them (tocilizumab and teprotumumab) are very promising but further evaluation is needed before we can establish their role in clinical care. Agents identified as beneficial in Graves' disease management will likely be tested in Graves' ophthalmopathy as well. In the coming years, our main clinical responsibility will be to find the proper balance between the benefits and potential risks of these incoming therapies, and to identify the subgroups of patients where this ratio is most likely to favor a safe and successful therapeutic outcome.
\end{abstract}

\section{Introduction and Methods}

Graves' disease (GD) and Graves' ophthalmopathy (GO) are seen together in $\sim 30 \%$ of cases [1,2], while the rest of the cases are metachronous, with GD usually preceding GO. The course of these entities is interdependent to a good extent, particularly the course of GO being clearly influenced by the control of GD. On the other hand, the choice of therapy for GD does depend on the state of GO. In this article, we aim to discuss current and potential future approaches to the therapy of these two entities. The therapeutic options discussed here are not an exhaustive list but rather include those with available or planned clinical trial testing and with some promising results based on our assessment. We separated the sections of future therapies for $G D$ and $G O$ though we acknowledge that some of the drugs tested for GD will likely be tried in GO if proved efficacious and vice versa, as long as their target relates to thyroid stimulating hormone receptor $(\mathrm{TSHr})$ stimulating antibodies and $\mathrm{T}$ cells. Other therapies will be specific to one entity or the other, depending on where they interfere in the pathogenic cascade.

We searched PubMed for English language studies published over the last 5 years by using search terms "Graves" and "autoimmune hyperthyroidism". This resulted in 1600 results out of which 190 pertained to GD and GO management. We also searched for clinical trials for therapies currently under investigation for GD and 
$\mathrm{GO}$, using the clinicaltrials.gov database. From these and their references, we selected articles that added significantly to this field in addition to articles published before 1/1/2013.

\section{Graves’ Disease: Current Therapy}

There are 3 established choices for the treatment of GD including radioactive iodine (RAI), antithyroid drugs (ATDs) and thyroidectomy. We aim to discuss the typical approach to implementing these choices and then we will discuss the different scenarios where one may be preferred over the others for a particular patient ( $\triangleright$ Table 1). Overall, the American Thyroid Association guidelines [3] have been noncommittal in their approach to selecting an individual therapy and leave this to the patient and their physician after an assessment of individual preferences.

\section{Radioactive iodine (lodine-131)}

History, trends, and choice considerations in GD

The thyroid follicular cells take up RAI, releasing beta particles that damage the follicular cells thus reducing thyroid hormone levels. In 1941, Dr. Saul Hertz administered a mixture of I-130/I-131 as the first therapeutic dose of RAI to a patient with Graves' hyperthy- roidism at Massachusetts General Hospital. Since then, RAl's use increased and became the preferred treatment for clinical hyperthyroidism due to GD in the US [4, 5]. Over the last decade though, there has been a decline in RAl utilization, which probably now accounts for 1 st line therapy in $<50 \%$ of new GD cases, with a compensatory rise in ATD use [6]. A failure rate of $8 \%$ has been reported for RAI therapy in GD according to a recent study at Mayo Clinic [7]. $\mathrm{RAl}$ is preferred in certain subgroups that want definitive therapy for GD and either favor nonsurgical management or are individuals with significant comorbidities, previous neck surgery or neck radiation, or lack access to a high volume surgeon, all increasing the surgical risk. RAI is also preferred in individuals that prefer nonsurgical management of GD and have a low likelihood of complete remission with ATDs like high TSHr antibody (TRAb), large goiter, high ATD requirement or have contraindications to ATD or failure of ATDs to achieve euthyroidism [3,6]. Definite contraindications for RAl are active and moderate-to-severe GO as RAI therapy in GD is usually associated with an elevation in TRAb titer [8], pregnancy, lactation, coexisting thyroid cancer, inability to adhere to radiation safety guidelines, and women planning pregnancy within the next 6 months [3].

- Table 1 Overview of current established treatment modalities for Graves' disease.

\begin{tabular}{|c|c|c|c|c|}
\hline $\begin{array}{l}\text { Treatment } \\
\text { modality }\end{array}$ & Mechanism of action & Advantages & Role in GD & Adverse effects \\
\hline Radioactive iodine & $\begin{array}{l}\text { Destruction of thyroid } \\
\text { follicular cells by beta } \\
\text { particles leading to } \\
\text { reduced thyroid } \\
\text { hormone levels }\end{array}$ & $\begin{array}{l}\text { Rapid control of hyperthy- } \\
\text { roidism } \\
\text { High efficacy with } \\
\text { approximately } 80 \% \text { cure } \\
\text { (euthyroidism or hypothy- } \\
\text { roidism) in most patients } \\
\text { No risk of surgery or } \\
\text { anesthesia }\end{array}$ & $\begin{array}{l}\text { Preferred first line therapy in the US } \\
\text { until recently, especially preferred in } \\
\text { surgical comorbidities, ATD } \\
\text { contraindicated or failed, rapid } \\
\text { control of hyperthyroidism, planning } \\
\text { pregnancy }>6 \text { months later }\end{array}$ & $\begin{array}{l}\text { Short-term adverse effects } \\
\text { (radiation thyroiditis and } \\
\text { sialadenitis) are rare and usually } \\
\text { occur after high dose } \\
\text { Long term adverse effects are } \\
\text { possibly thyroid, stomach and } \\
\text { kidney cancer but there no clear } \\
\text { evidence is not definitive. }\end{array}$ \\
\hline $\begin{array}{l}\text { Antithyroid drugs } \\
\text { (Thionamides) } \\
\text { Methimazole (in US) } \\
\text { Carbimazole } \\
\text { (in Europe) } \\
\text { Propylthiouracil }\end{array}$ & $\begin{array}{l}\text { Interference with TPO } \\
\text { thus inhibiting thyroid } \\
\text { hormone synthesis } \\
\text { PTU also blocks } \\
\text { peripheral conversion } \\
\text { of T4 to T3. } \\
\text { Possible immunomod- } \\
\text { ulatory effect }\end{array}$ & $\begin{array}{l}\text { No hypothyroidism unless } \\
\text { very high dosage } \\
\text { Does not worsen GO } \\
\text { No risk of surgery or } \\
\text { anesthesia }\end{array}$ & $\begin{array}{l}\text { Preferred as definitive therapy when } \\
\text { high likelihood of remission (mild } \\
\text { disease, small goiter, women, low or } \\
\text { negative TRAb); pregnancy (PTU } \\
\text { preferred in first trimester); when } \\
\text { RAl and thyroidectomy have more } \\
\text { risk than benefit. } \\
\text { Also for rapid control of hyperthyroid- } \\
\text { ism prior to thyroidectomy or RAI }\end{array}$ & $\begin{array}{l}\text { Serious adverse effects include } \\
\text { agranulocytosis and hepatotox- } \\
\text { icity, which usually occur within } \\
\text { the first 3-6 months of therapy } \\
\text { Small vessel vasculitis can occur } \\
\text { after long term treatment } \\
\text { Allergic cutaneous reactions }\end{array}$ \\
\hline $\begin{array}{l}\text { Total or near-total } \\
\text { thyroidectomy }\end{array}$ & $\begin{array}{l}\text { Removal of source of } \\
\text { thyroid hormone } \\
\text { production }\end{array}$ & $\begin{array}{l}\text { Rapid control of hyperthy- } \\
\text { roidism } \\
\text { Highest efficacy with } 100 \% \\
\text { success rate } \\
\text { Useful for large symptomatic } \\
\text { goiter or coexistent thyroid } \\
\text { cancer } \\
\text { Does not worsen GO }\end{array}$ & $\begin{array}{l}\text { Preference in larger goiter with } \\
\text { compressive symptoms, concomi- } \\
\text { tant thyroid malignancy or } \\
\text { hyperparathyroidism, moder- } \\
\text { ate-to-severe GO, high TRAb }\end{array}$ & $\begin{array}{l}\text { Transient or permanent } \\
\text { hypoparathyroidism causing } \\
\text { hypocalcemia, transient or } \\
\text { permanent recurrent or superior } \\
\text { laryngeal nerve injury, postopera- } \\
\text { tive bleeding, and anesthesia } \\
\text { complications }\end{array}$ \\
\hline $\begin{array}{l}\text { Symptomatic } \\
\text { therapy } \\
\text { Beta blockers } \\
\text { Calcium channel } \\
\text { blockers }\end{array}$ & $\begin{array}{l}\text { Antagonism of } \\
\text { sympathetic response } \\
\text { to elevated thyroid } \\
\text { hormone levels }\end{array}$ & $\begin{array}{l}\text { Rapid symptom control as } \\
\text { sole therapy for mild } \\
\text { hyperthyroidism or adjuvant. }\end{array}$ & $\begin{array}{l}\text { Used in patients with significant } \\
\text { symptoms especially tachycardia } \\
\text { from hyperthyroidism }\end{array}$ & $\begin{array}{l}\text { May worsen bronchospastic } \\
\text { asthma, obstructive airway } \\
\text { disease, or Raynaud's disease }\end{array}$ \\
\hline
\end{tabular}




\section{Accomplishing RAl therapy in GD}

Prior to RAl administration, pregnancy should be ruled out. RAI can precipitate short-term worsening of hyperthyroidism through release of preformed thyroid hormone [9], with thyroid storm occurring in rare instances [10]. Hence, pre-therapy with $\beta$ blockade should be considered for symptomatic patients, when free T4 is more than 2-3 times the upper limit of normal as well as for asymptomatic patients who are at increased risk of complications from worsening of hyperthyroidism (e. g., elderly or those with cardiac comorbidities). ATD pretreatment should also be considered in these patients noting that methimazole needs to be discontinued at least 3 days prior to RAI administration. Pretreatment with supersaturated potassium iodide (SSKI) may be an alternative to those allergic to ATDs. Patients should avoid foods or supplements containing excess iodine, and a low iodine diet is preferred for those with relatively low RAI uptake. A sufficient dose of RAI needs to be administered to render the patient hypothyroid, which usually is approximately $10-15 \mathrm{mCi}$ [3]. This can be achieved either by administering a fixed dose or a dose calculated based on the thyroid size and its ability to take up RAI. A meta-analysis done in 2009 showed equally successful treatment outcomes with either approach but the studies had heterogeneity [11]. A recent study evaluating $120 \mathrm{GD}$ patients found that at the end of 6 months, treatment failure was higher at $37.5 \%$ in the calculated dose group (utilizing $160 \mathrm{microCi} / \mathrm{g}$ of thyroid tissue) versus $19.6 \%$ in the fixed dose group, suggesting preference for the latter approach of RAI administration [12]. However, in our experience at Mayo Clinic with calculated dose of $200 \mathrm{microCi} / \mathrm{gram}$ of thyroid tissue we noted a success rate of $92 \%$ [7], leading us to prefer this approach as opposed to fixed RAl dosing.

\section{Post-RAI therapy management}

Re-initiation of methimazole 3-7 days after RAl administration reduces free T4 [13], hence should be considered in those with increased risk of complications due to worsening hyperthyroidism. Continuation of ATDs during RAI administration is not recommended due to concern for reduced treatment efficacy. Radiation thyroiditis and sialadenitis are rare side effects usually associated with a high dose of RAI. As for long-term adverse effects, a recent meta-analysis found no increase in overall cancer risk, however a trend towards higher rates of thyroid, stomach and kidney cancer leaves this question open for more studies [14]. Hypothyroidism can occur from 4 weeks onwards, with $40 \%$ of patients being hypothyroid by 8 weeks, and more than $80 \%$ by 16 weeks [15]. Hence, surveillance for hypothyroidism in needed 1-2 months after RAI therapy, further biochemical monitoring at 4-6-week intervals for the $1 \mathrm{st}$ 6 months or until the patient becomes hypothyroid and is on a stable dose of thyroid hormone replacement [3].

\section{Thyroidectomy}

\section{History, trends, and choice considerations in GD}

Historically, thyroidectomy had been the first and only method of treating GD until the early 1940's when ATD and RAI came along. Since then, it became the least utilized approach to GD therapy due to the logistical advantages of the other two options. However there are some theoretical advantages to thyroidectomy in GD: in addition to removing the source of uncontrollable production of thyroid hormones, there is evidence that this decrease in antigen supply is followed by improvement in TRAb titer [8]. The clinical implications of this outcome are still being debated regarding impact on other autoimmune manifestations related to TRAb, like GO. Furthermore, near-total or total thyroidectomy has demonstrated the highest success rate for control of hyperthyroidism (100\%) among GD therapies [7]. This is also better than subtotal thyroidectomy which is no longer an acceptable approach for these patients. Overall, thyroidectomy is the preferred approach for a number of subgroups: women planning pregnancy within the following 6 months, thyroid-related compressive symptoms (dyspnea, dysphagia, or dysphonia), large goiters and/or relatively low RAl uptake, concomitant conditions requiring surgery (thyroid malignancy, primary hyperparathyroidism), and moderate-to-severe and active GO that are not interested or intolerant to ATDs [3]. Definite contraindications include high surgical risk (e.g., end-stage cardiopulmonary disease) or limited life expectancy (e.g., endstage cancer). Pregnancy is a relative contraindication where thyroidectomy is considered only when rapid control of hyperthyroidism is required and ATDs are ineffective or contraindicated, in which case it should be ideally performed in the 2 nd trimester [3].

\section{Accomplishing thyroidectomy in GD}

Hyperthyroidism should be controlled whenever possible by ATDs with or without beta blockade prior to thyroidectomy to minimize the surgical risk. In hyperthyroid individuals, the stress of surgery or anesthesia can precipitate thyroid storm although data from Japan [10] failed to identify any such event after thyroidectomy. Preoperative iodine use in the form of SSKI or Lugol's solution administered 7 days before surgery decreases thyroid blood flow, vascularity and intraoperative blood loss during thyroidectomy [16]. Rapid preparation for emergent thyroidectomy can also be facilitated by the use of iopanoic acid (not available in US), dexamethasone or cholestyramine [17]. Preoperative assessment of calcium and vitamin D stores followed by replacement as necessary decreases the risk of postoperative hypocalcemia due to transient hypoparathyroidism [18]. Evaluation of calcium status is also useful to understand if silent hyperparathyroidism is present simultaneously and adjust surgical planning accordingly. For the best surgical outcome, it is desirable to use a high volume thyroid surgeon (one who performs $>25$ thyroid surgeries per year) as this approach significantly minimizes the risk of complications [19]. The residual surgical risks include transient or permanent hypoparathyroidism causing hypocalcemia (0-12.4\%), transient or permanent recurrent or superior laryngeal nerve injury leading to vocal cord paralysis (0.9-2.8\%), neck hematomas $(2.8 \%)$, and anesthesia complications $[7,20]$.

\section{Post-thyroidectomy management}

Post-surgical monitoring should include serum calcium with or without intact parathyroid hormone (PTH) levels. Monitoring PTH levels in the immediate postoperative phase has the ability predict symptomatic hypocalcemia if PTH value is low [21] but normal PTH levels are not able to guarantee normocalcemia [22, 23], thus suggesting that vitamin-D insufficiency is likely to be present in these cases. Treatment for hypocalcemia should start with oral calcium and calcitriol, and hydrochlorothiazide should be added in treatment-resistant cases while IV calcium therapy is reserved for se- 
verely symptomatic hypocalcemia. Teriparatide administration in the postoperative period has yielded encouraging results in improving severe and symptomatic hypocalcemia but this requires further research before being implemented as routine clinical practice [24]. Beta blockers should be weaned slowly after surgery while levothyroxine is started (usually weight based $1.6 \mathrm{mcg} / \mathrm{kg} /$ day) and thyroid levels should be checked 6-8 weeks later [3].

\section{Antithyroid drugs}

History and choice considerations in GD

ATDs or thionamides include Propylthiouracil (PTU), Methimazole (MMI, in the United States) and Carbimazole (in Europe). They entered clinical use in the 1940s. Their mechanism of action is inhibition of thyroid peroxidase (TPO) enzyme thus inhibiting thyroid hormone synthesis; in addition, PTU blocks the peripheral conversion of T4 to T3 [25]. ATDs are thought to have an additional immunomodulatory effect and are associated with decrease in TRAb levels in many patients $[8,26]$. ATDs are utilized as the main therapy for controlling hyperthyroidism with the goal of complete remission in a large percent of cases but they are also employed for rapid biochemical control prior to definitive therapy with RAI or thyroidectomy. They carry the advantage of avoiding long term hypothyroidism as opposed to RAI and thyroidectomy but have lower long term success rates than the other two options. ATDs are preferred in patients with a high likelihood of remission (mild disease, small goiter, women, low or negative TRAb), pregnancy, high surgical risk, inability to follow radiation safety regulations, previously operated or irradiated necks, lack of access to a high volume thyroid surgeon. They are absolutely contraindicated in the setting of previous major adverse reaction to another ATD [3]. Among the different ATDs, MMI has a longer duration of action; hence it is effective as daily dose in most cases as opposed to PTU which needs to be administered 2-3 times per day. MMI is usually preferred over PTU except during thyroid storm for rapid control of hyperthyroidism, allergy to MMI, and 1st trimester of pregnancy [3].

\section{Accomplishing ATD therapy in GD}

ATD dose should be adjusted to T4/T3 level, goiter size, and symptoms. The ATA task force [3] recommends MMI daily dosing of $5-10 \mathrm{mg}$ if free T4 is $1-1.5$ times the upper limit of normal, $10-20 \mathrm{mg}$ if free T4 is 1.5-2 times the upper limit of normal, and $30-40 \mathrm{mg}$ if free T4 is $2-3$ times the upper limit of normal. Once the patient is euthyroid, the dose of MMI can usually be decreased by $30-50 \%$ and biochemical testing repeated in 4-6 weeks. Once euthyroid levels are achieved with minimal dose, clinical and biochemical evaluation can be done at 3 month intervals for 12-18 months, which can be further increased to 6 month intervals in case of long term MMI (>18 months) [3]. ATDs are sometimes combined with levothyroxine in what is called "block and replace". This is a regimen that is not endorsed equally across the world but when employed, it is reserved for patients with frequent fluctuations between hypo- and hyperthyroidism. With this approach, a combination of fixed dose ATD (block) and levothyroxine (replace) is utilized to maintain euthyroidism. The main benefit of this regimen is the decreased need for laboratory testing and clinic visits, however it is not clear if there is any advantage towards the achievement of complete remission [27].
The usual duration of ATD therapy is 12-18 months, and at that time the TRAb titer is helpful for deciding ATD discontinuation because elevated TRAb is associated with relapse rates of $80-100 \%$ and low or undetectable TRAb with relapse rates of $20-30 \%[8,28]$. Schott et al. demonstrated that all GD patients with 2 nd generation TRAb > $6 \mathrm{IU} / \mathrm{l}$ and anti-TPO > $5000 \mathrm{IU} / \mathrm{ml}$ tested shortly after GD diagnosis had relapse of hyperthyroidism [29]. Patients are considered to be in remission if they remain euthyroid for 1 year after ATD discontinuation. Remission rates have been classically reported as $20-30 \%$ in the US after 12-18 months of therapy; however, a recent study at Mayo Clinic showed remission rate of $52 \%$ [7], which is close to that reported in Europe at $50-60 \%$ after 5 years [30] and Japan at $68 \%$ after 2 years of therapy [31].

If TRAb is elevated at $12-18$ months, ATD can be continued or the patient considered for alternative definitive therapy with RAI or surgery. This is supported by studies demonstrating that 2nd generation TRAb level $>7.5 \mathrm{IU} / \mathrm{l}$ at the end of 12-month ATD therapy or $>3.85 \mathrm{IU} / \mathrm{l}$ at the end of 18 -month ATD predicted relapse with a specificity of 96-97\% [28, 32]. Longer-term ATD therapy with $\mathrm{MMI}$ has gained traction in recent years. It is a reasonable therapy for younger patients with mild disease who are well controlled on low-dose ATD [33]. A meta-analysis by Azizi et al. that included studies done till 2011 demonstrated that i) long-term ATD treatment induced a remission rate of $57 \%$; ii) the rate of complications was $19.1 \%$, of which only $1.5 \%$ were major complications; and iii) the annual remission rate for each year of treatment was $16 \%$ [34]. A recent study by Villagelin et al. in 2015 further supported this concept by reporting that therapy with low dose MMI for 12-24 months was both efficient and safe with no major side effects, and also had a lower rate of persistent GO as compared to RAI [35]. A second course of ATD can also be considered for GD patients after the first relapse because the chance of remission is similar to the one after the first ATD treatment course [36]. The same authors found that the remission rate declines significantly after two relapses; suggesting long term low-dose ATD maintenance or ablative treatment should be discussed at that point [36].

\section{Adverse effects of ATDs}

Adverse effects have been reported in $17.3 \%$ of those treated with ATDs, most commonly dysgeusia (4.4\%), rash (2.8\%), nausea/gastric distress (2.4\%), pruritus (1.6\%), and urticaria (1.2\%) [7]. Clinical monitoring is required for serious adverse effects including agranulocytosis and hepatotoxicity, which usually occur within the first 3-6 months of initiating ATDs. Fortunately, these are very rare thus laboratory testing is done only during febrile illness and at the onset of pharyngitis or symptoms of hepatocellular injury. Agranulocytosis is reported to be more common with PTU as compared to MMI [37] and more with higher dose of $30 \mathrm{mg}$ of MMI as compared to $15 \mathrm{mg}$ [38]. Genome wide association studies have identified certain HLA-B and HLA-DR polymorphisms linked to higher risk of ATD-associated agranulocytosis [39, 40]. Hepatotoxicity from MMI is usually cholestatic but hepatocellular disease may also occur [41]. In contrast, PTU can lead to fulminant hepatic necrosis [42], and a review of such cases and their outcome (frequently patients' death or liver transplantation) in 2009 [43] led to the current preference for MMI as the 1 st choice ATD for GD. However, recent investigations have challenged this pattern, with one study 
showing no difference in rates of cholestasis with MMI and PTU [44] and another showing similar rates of liver failure with both [45]. It is recommended that ATDs be discontinued if transaminase levels reach $>3$ times the upper limit of normal or if levels elevated at the onset of therapy increase further [3]. ATD induced hepatotoxicity or preexisting hepatic dysfunction from hyperthyroidism [46] may lead to preference for RAl or thyroidectomy in these patients. Small vessel vasculitis has been reported to occur usually after long term ATD treatment [47], but can occur at varying times and after exposure to various doses of PTU with a median time to occurrence of 38 months [48]. This is usually managed by ATD discontinuation and corticosteroid administration. In case of allergic cutaneous reactions to $\mathrm{MMI}$ at the initial treatment for GD, one study reported that such patients can tolerate a low dose of MMI without adverse effects once euthyroidism has been restored [49].

\section{Symptomatic therapy}

Symptomatic therapy is used in all patients with significant symptoms from hyperthyroidism. Beta adrenergic blocking drugs are used to control the sympathetic response to elevated thyroid hormone levels. These include propranolol, atenolol, metoprolol, nadolol, and the intravenous esmolol. Of these, atenolol and metoprolol have relative beta- 1 selectivity, hence should be preferred in those with quiescent bronchospastic asthma, mild obstructive airway disease or Raynaud's phenomenon in whom heart rate control is essential. Calcium channel blockers can be used in patents who do not tolerate beta adrenergic blocking drugs [3].

\section{Trends in established therapy choices}

Many factors including clinical features as well as patient preferences need to be considered when choosing a therapy for GD, and preference for one option over the other exists in different parts of the world. According to surveys comparing clinical practice patterns in the management of GD in US and Europe, first line treatment was ATD in Europe as compared to RAI in US. Both areas were similar in terms of managing GO risk by adding steroid prophylaxis when RAI treatment was selected in the presence of mild Graves' orbitopathy and/or associated risk factors for its occurrence/exacerbation; and PTU being the preferred ATD in pregnancy in the first trimester and $\mathrm{MMI}$ in the second and third trimesters [4, 5]. However, analysis of administrative claims data throughout the United States from 2004 to 2013 showed that RAI as the first line therapy for GD has been declining and ATD use has been increasing [6].

\section{Rarely employed therapeutic choices ( $\triangleright$ Table 2 )}

\section{Selenium}

The use of selenium in GD has been proposed given the presence of reactive oxygen species in the thyroid and the known antioxidant effect that selenium provides. While some studies with a mixture of antioxidants found beneficial results on biochemical parameters [50], studies looking directly at the benefit of adding selenium to MMI had mixed results [51-54]. One such study [53] showed a positive result in terms of biochemical control of hyperthyroidism while two RCTs did not show any benefit for improving hyperthyroidism in the short term [52] and response or recurrence rates in GD [54]. This discrepancy might be related to the different level

- Table 2 Overview of current rarely employed and adjuvant treatment modalities.

\begin{tabular}{|c|c|c|c|c|}
\hline $\begin{array}{l}\text { Treatment } \\
\text { modality }\end{array}$ & Mechanism of action & Advantages & Role in GD & Adverse effects \\
\hline $\begin{array}{l}\text { Potassium iodide } \\
\text { Supersaturated } \\
\text { potassium iodide } \\
\text { (SSKI) } \\
\text { Lugol's iodine } \\
\text { solution }\end{array}$ & $\begin{array}{l}\text { Reduces iodine organifica- } \\
\text { tion and thyroid hormone } \\
\text { secretion } \\
\text { Reduces thyroid vascularity } \\
\text { and intraoperative blood loss } \\
\text { when used prior to } \\
\text { thyroidectomy }\end{array}$ & $\begin{array}{l}\text { No concern for adverse } \\
\text { effects from other } \\
\text { definitive options } \\
\text { Useful when there is } \\
\text { contraindication or allergy } \\
\text { to ATDs }\end{array}$ & $\begin{array}{l}\text { Adjunct to ATDs for moderate to severe } \\
\text { hyperthyroidism } \\
\text { Prior to thyroidectomy for GD } \\
\text { No strong evidence to support its use as } \\
\text { sole therapy }\end{array}$ & $\begin{array}{l}\text { Mouth irritation and bad } \\
\text { taste from Lugol's iodine } \\
\text { solution }\end{array}$ \\
\hline Lithium & $\begin{array}{l}\text { Blocks release of thyroid } \\
\text { hormone }\end{array}$ & $\begin{array}{l}\text { Rapid but transient control } \\
\text { of hyperthyroidism }\end{array}$ & $\begin{array}{l}\text { Adjuvant to ATD and RAI for GD } \\
\text { hyperthyroidism } \\
\text { No strong evidence to support its use as } \\
\text { sole therapy }\end{array}$ & $\begin{array}{l}\text { Arrhythmia, diabetes } \\
\text { insipidus, skin abnormali- } \\
\text { ties, neurologic side-effects }\end{array}$ \\
\hline Plasmapheresis & $\begin{array}{l}\text { Clears thyroid hormones, } \\
\text { cytokines, deiodinase } \\
\text { enzyme, and Graves' } \\
\text { antibodies }\end{array}$ & $\begin{array}{l}\text { Rapid but transient control } \\
\text { of thyrotoxicosis } \\
\text { Useful when there is } \\
\text { contraindication or } \\
\text { resistance to ATDs }\end{array}$ & $\begin{array}{l}\text { Temporizing measure for rapid control } \\
\text { of thyrotoxicosis prior to thyroidectomy }\end{array}$ & $\begin{array}{l}\text { Transfusion reaction, } \\
\text { citrate-related nausea and } \\
\text { vomiting, vasovagal or } \\
\text { hypotensive reactions, } \\
\text { respiratory distress, and } \\
\text { tetany or seizure }\end{array}$ \\
\hline $\begin{array}{l}\text { Bile acid } \\
\text { sequestrants } \\
\text { Cholestyramine }\end{array}$ & $\begin{array}{l}\text { Bind to thyroid hormones in } \\
\text { enterohepatic circulation } \\
\text { thus increasing their } \\
\text { clearance }\end{array}$ & $\begin{array}{l}\text { Additional control of } \\
\text { thyrotoxicosis by a } \\
\text { mechanism different than } \\
\text { definitive therapies }\end{array}$ & $\begin{array}{l}\text { Adjunct to ATD for severe hyperthyroidism } \\
\text { For rapid control of hyperthyroidism in } \\
\text { preparation for thyroidectomy }\end{array}$ & Bloating \\
\hline $\begin{array}{l}\text { Corticosteroids } \\
\text { Dexamethasone } \\
\text { Hydrocortisone }\end{array}$ & $\begin{array}{l}\text { Inhibit T4 to T3 conversion } \\
\text { by inhibiting deiodinase }\end{array}$ & $\begin{array}{l}\text { Rapid control of } \\
\text { thyrotoxicosis }\end{array}$ & $\begin{array}{l}\text { Adjunct in severe hyperthyroidism or } \\
\text { thyroid storm } \\
\text { For rapid control of hyperthyroidism } \\
\text { prior to thyroidectomy }\end{array}$ & $\begin{array}{l}\text { Dose and duration } \\
\text { dependent adverse effects }\end{array}$ \\
\hline
\end{tabular}


of selenium sufficiency in the populations studied. Given the availability of other effective therapies for GD, we don't support the use of selenium for GD outside of research protocols.

\section{Lithium}

Lithium blocks the release of thyroid hormone but has prominent side effects. It can be considered as a temporizing or adjuvant therapy for hyperthyroidism. Treatment with lithium prevents serum thyroid hormone increase after ATD withdrawal and RAI therapy in $\mathrm{GD}[55,56]$, and it has also been used to control hyperthyroidism when ATD is not tolerated [57]. However, due to risk of arrhythmia, diabetes insipidus, skin abnormalities and multiple neurologic side effects, lithium treatment is rarely employed.

\section{Potassium iodide}

Potassium iodide acutely lowers thyroid hormone levels by reducing hormone secretion and inhibiting iodide organification; the current paradigm suggests that patients' will escape this acute inhibition therefore its main use is short term, mainly as adjuvant before thyroidectomy as discussed in the thyroidectomy section. It has been tested as adjunct to ATD in an RCT whose results showed that MMI $15 \mathrm{mg}$ and inorganic iodine $38 \mathrm{mg} /$ day resulted in higher percentage of biochemical euthyroidism and lower frequency of adverse effects as compared to MMI $30 \mathrm{mg} /$ day [58]. Low dose potassium iodide has been used to control mild hyperthyroidism after RAI. It has also been used as the sole therapy in patients with mild hyperthyroidism that are intolerant to ATDs and have a contraindication to RAI or surgery [59].

\section{Plasmapheresis or therapeutic plasma exchange}

Plasmapheresis works by eliminating large molecular substances, including protein-bound thyroid hormones, from the plasma through extracorporeal blood purification technique [60]. This is employed in cases of severe thyrotoxicosis when rapid correction of thyroid hormone excess is required, usually in preparation for thyroidectomy. While reportedly it can also clear various cytokines, deiodinase enzymes and TSHr antibodies [61]; there are no data to support its impact on GO and pretibial myxedema, and its cost and potential side-effects need to be carefully considered.

\section{Bile acid sequestrants}

Bile acid sequestrants like cholestyramine bind to thyroid hormones in the enterohepatic circulation, removing them from circulation. They can be used as adjunct to ATDs or for rapid control of hyperthyroidism in preparation for thyroidectomy [17]. Bloating and the need for multiple daily doses are their main limiting factors.

\section{Corticosteroids}

Corticosteroids inhibit T4 to T3 conversion by inhibiting deiodinase type 2 [62], hence are useful for rapid control of thyrotoxicosis. They are employed as an adjunct to therapy in thyroid storm or prior to urgent thyroidectomy for uncontrolled thyrotoxicosis. Significantly high doses are required for this effect thus the typical approach involves administration of $300 \mathrm{mg}$ of hydrocortisone IV load followed by $100 \mathrm{mg}$ IV every $8 \mathrm{~h}$.

\section{Graves' disease management in pregnancy}

Graves' disease affects approximately $0.1 \%$ of pregnancies and carries a substantial risk of adverse effects in mother and child, especially if it is inadequately treated [63]. Ideally, thyrotoxic women should be rendered stably euthyroid before attempting pregnancy [64]. Both MMI and PTU are associated with teratogenesis. MMI-associated birth defects occur at a rate of 3-4\% (e. g., choanal atresia, esophageal atresia, aplasia cutis) especially if the fetus is exposed during gestational weeks 6-10 [65]. The risk of birth defects with PTU is 2-3\% though these are less severe (e. g., renal cysts, preauricular and branchial sinus or fistula) $[65,66]$. Therefore, ATDs should be ideally avoided in the first trimester of pregnancy. This is feasible if hyperthyroidism is very mild, however ATDs are the mainstay of treatment for clinically-significant GD during pregnancy. When necessary, PTU is generally favored due to lower risk of severe birth defects. In the 2 nd and 3rd trimester, given the risk of severe hepatotoxicity with PTU the recommendations have been focused on reverting to the use of MMI but there is an ongoing debate about the potential for dysthyroidism during the conversion process. Regardless of the choice of agent, ATDs should be administered at the lowest effective dose targeting maternal serum free $\mathrm{T} 4$ or total $\mathrm{T} 4$ at the upper limit or moderately above the reference range [64]. Thyroid hormones should be monitored every 4 weeks to guide dose adjustment and hopefully therapy discontinuation, which tends to occur in the $2 \mathrm{nd}$ and $3 \mathrm{rd}$ trimester. TRAb should be measured at diagnosis and, if elevated, repeated at 18-22 weeks and again at 30-34 weeks of gestation [3] to guide the assessment and management of potential fetal thyrotoxicosis. TRAb should be monitored in the same manner even if the mother has been treated with RAI or surgery prior to pregnancy. If despite the above measures, severe hyperthyroidism persists and thyroidectomy is required, it is optimally performed during the second trimester [64]. Post-partum the risk for GD recurrence is increased, however these patients are more prone to undergo remission after a second course of MMI treatment, thus warranting a conservative therapeutic approach [67].

When GD is diagnosed prior to pregnancy and the patient is taking MMI, it should be switched to PTU or withdrawn as soon as pregnancy is confirmed. The risk of relapse after ATD withdrawal in early pregnancy is high in those treated for a short period (<6 months), who have suppressed TSH, who require $>5-10 \mathrm{mg}$ of MMI per day, who have GO or a large goiter, and those with high TRAb [64]. When this risk is considered high, then instead of ATD withdrawal, therapy should be switched to PTU during the first trimester. TRAb should be monitored in the same manner as mentioned above even if the mother has been treated with RAI or surgery prior to pregnancy.

\section{Graves’ Disease: Potential Future Options}

\section{Immunotherapy}

Over the last few years there have been a number of attempts at revamping the approach to GD by targeting the immune system.

\section{Rituximab}

Rituximab, a monoclonal antibody targeting the CD20 complex on $B$ cells has been employed in a clinical trial with 20 patients treated 
with MMI for 4 months and then assigned in a non-randomized manner to observation vs use of rituximab per the lymphoma protocol $[68,69]$. Four out of 10 patients in the rituximab group remained in remission compared with none in the control group. Due to its low efficacy, high cost and risk of side-effects, the authors did not advocate its use in GD. No further reports have been published on this approach.

\section{CFZ533}

Another trial that has been registered on clinicaltrials.gov for GD studied the use of a new biological agent, CFZ533. This agent is an Fc-silenced fully human anti-human CD40 monoclonal antibody, incapable of B cell depletion but a potent inhibitor of CD40 pathway activation. By affecting CD40-CD154 interactions that occur between antigen-presenting cells and T cells, it is presumed to modulate humoral immunity, germinal center formation, affinity maturation and memory B cell development. The trial registered (ClinicalTrials.gov Identifier: NCT02713256) was a phase 2 trial whose primary outcome was the percent of patients that normalized TSH at 3 months of therapy. The results of the trial have not been announced yet. A measure of the promising nature of this immunotherapy is reflected in the fact that this agent is also being tested in renal transplant graft survival, rheumatoid arthritis, Sjogren's syndrome and severe myasthenia gravis.

\section{ATX-GD-59}

The pervasive problem with these approaches is that the modulation of the immune system is non-specific and the risk of infections is always a concern. Therefore, a better approach would be to target the specific immune reaction that is pathologic. This can be achieved by targeting regulatory $T$ cells (Tregs) that are activated by antigens just like the rest of $T$ cells but whose main role is to suppress an immune response against the antigen they've learned to recognize. Such an approach has been pursued by the investigators testing ATX-GD-59 (ClinicalTrials.gov Identifier: NCT02973802). This approach is expected to operate akin to a tolerogenic vaccine for GD by eliminating from the vaccine mixture the adjuvants, the typical stimulants of the immune system that are included in classical vaccine formulations. In this case, the investigators used a mixture of three peptides aiming to generate Tregs that are activated by TSHr and thus suppress immune responses against this antigen. The trial is a phase 1 study to assess the safety and biological activity of this agent in patients with GD not currently treated with antithyroid therapy. The protocol allows for open label dose titration and describes intradermal injection on 10 occasions, each two weeks apart. The trial started on September 2016, it has just been completed (February 2018) and the results are expected to be released in the coming months.

\section{Treg therapy}

Another promising approach is that of cell based therapy looking at the role of Tregs in suppressing unwanted immune responses. The plan is to collect these cells from patients, then "train" them to recognize the autoantigen involved in the particular pathophysiology affecting that individual (i. e., TSHr in this case) and then re-administering the cells to the patient with the expectation that they will now be able to suppress the immune response against the autoan- tigen they have just been exposed to. The best approach to "train" the Tregs in the lab is the focus of current work. The use of a chimeric antigen receptor has been tested for this purpose in oncological research and is now under study for Treg manipulation [70].

\section{$\mathrm{K} 1-70$}

It would seem that blocking the TSHr from the stimulating activity of antibodies would be the most effective way of controlling the hyperthyroidism caused by GD. To that end, a TSHr antagonist called K1-70 has been developed [71]. This is a human monoclonal IgG autoantibody that when administered to rats caused a dose dependent decrease in thyroid hormone levels and was also able to cancel the stimulatory effect of the stimulating monoclonal autoantibody M22 IgG on the rats' thyroid function [72]. It is presently undergoing clinical evaluation in a phase 1 multicenter trial in UK (ClinicalTrials.gov Identifier: NCT02904330), which is expected to be completed in the first half of 2020 .

\section{Ultrasound based therapies}

\section{High intensity focused ultrasound}

High intensity focused ultrasound (HIFU) is a proposed therapeutic modality relying heavily on physics as opposed to immunobiology. This experimental approach involves the application of a high-energy focused ultrasound beam for thermal tissue ablation within a targeted zone. Its use has been reported in benign thyroid nodules [73] and a trial in relapsed GD was recently completed (ClinicalTrials.gov Identifier: NCT02685514). The investigators Lang et al. postulate that the heat energy generated from HIFU could be used to ablate the thyroid parenchyma, making this approach the non-radioactive equivalent of RAI therapy.

\section{Radiofrequency ablation}

Over the last decade, radiofrequency ablation (RFA) has been found to be a well-tolerated and effective method of inducing shrinkage in benign thyroid nodules by inducing tissue necrosis and fibrosis. The energy, converted into heat at tissue level, is delivered through a special ablation electrode under ultrasound guidance. The shrinkage has led to improvement in both compressive and esthetic concerns related to large thyroid nodules. In addition, this approach has been tested in toxic adenomas for control of thyroid levels. Repeated trials, mainly in South Korea and Italy, have found the rate of euthyroidism post-therapy around $50 \%$ with the majority of other cases having a decrease in ATD therapy [74-76]. Obviously, these therapies will have to undergo further evaluations before they can be employed as part of the established armamentarium for hyperthyroidism. With respect to ultrasound based therapies, the barriers will likely be availability of technology as well as the specialist expertise for performing these therapies in a safe and effective manner. Currently, only one US center has reported its experience with RFA technology for benign thyroid disease [77].

\section{Graves' Ophthalmopathy: Current Therapy}

After confirmation of GO diagnosis, smoking cessation, restoration of euthyroidism and initiation of local protective measures should 
be instituted in all cases. In parallel, there should be an assessment of disease activity [through Clinical Activity Score (CAS)], severity and presence of sight-threatening manifestations. If dysthyroid optic neuropathy (DON) or corneal ulceration are present, then GO is considered sight-threatening. For DON, treatment starts with intravenous (IV) glucocorticoids (GCs) though some centers proceed straight to orbital decompression. In cases of corneal ulceration, priority is given to local measures to improve globe coverage and healing. If DON is absent, further strategies are employed based on disease activity (CAS) and severity. For mild active disease, observation or selenium are the next steps, but occasionally GCs are employed if quality of life $(\mathrm{QoL})$ is significantly impaired or if the disease progresses. For moderate-to-severe and active disease, IV GCS are the standard first treatment choice while orbital radiotherapy can be added to control diplopia, and orbital decompression considered if disease progresses. For mild and inactive disease, local measures are enough. Once moderate-to-severe disease becomes inactive, rehabilitative surgery is usually required after there has been evidence of disease stability for at least 3 months [78, 79].

\section{Smoking cessation}

Smoking is associated with higher prevalence and severity of GO, and a higher likelihood of progression or de novo occurrence of $\mathrm{GO}$ after RAI therapy [80]. Smoking also curtails the effectiveness of immunosuppressive treatment for $\mathrm{GO}$ [81], and smoking cessation has been associated with lower risk of adverse outcomes from GO including diplopia and exophthalmos [82]. Hence every patient with GD irrespective of the presence of $\mathrm{GO}$ should be advised to quit smoking.

\section{Management of hyperthyroidism}

Management of hyperthyroidism is essential in preventing the development and worsening of GO. In case of mild active GO and no risk factors for deterioration, RAI, thyroidectomy and ATD are equally acceptable therapeutic options. However, RAI has been reported to worsen GO by 3.2-5.8 times [ 83,84$]$, and also to be associated with a significantly higher risk of de novo development of GO (38.7\% vs. $21.3 \%$ ) as compared to ATD [85]. In order to mitigate this risk, concomitant use of oral GCs is recommended in cases of mild and active GO [86]. In active and moderate-to-severe or sight-threatening GO, RAl is contraindicated, and ATDs and surgery are the preferred therapeutic options [87]. Given that some of these cases have a protracted active phase of $\mathrm{GO}$, it is reassuring to know that long term ATD therapy has been safely utilized in this population while waiting for patients to undergo remission of moderate-to-severe GO $[88,89]$.

\section{Local measures}

The eyelid retraction and proptosis predispose to increased corneal and conjunctival exposure. Therefore, local measures to maintain the tear film and good lubrication are recommended as first line for mild GO along with measures to decrease photophobia and the sensation of foreign body related to local irritation. These include artificial tears such as sodium hyaluronate as well as sunglasses or goggles. Ointments with osmoprotective properties such as carboxymethylcellulose offer additional epithelial protection and symptom control especially since GO is characterized by increased osmolarity [90].

\section{Selenium}

The effect of selenium treatment in $\mathrm{GO}$ is achieved mainly due to its anti-inflammatory and antioxidant nature. A 6 month selenium supplementation can be used for all mild active cases of $\mathrm{GO}$ with a relatively short duration [78]. This is based on a multicenter placebo-controlled RCT where 6 months of sodium selenite $(100 \mu \mathrm{g}$ twice daily, corresponding to $93.6 \mu \mathrm{g}$ of elemental selenium/day) showed improvement in QoL and overall ocular involvement at 6 months compared to the placebo group (overall ocular improvement 61 vs. 36\%) and improvement was maintained at 12 months, after selenium withdrawal; in addition, the rate of progression of GO to more severe forms after intervention was significantly lower in the selenium group and the side-effect profile of this antioxidant mineral was extremely benign [91].

\section{Glucocorticoids}

Oral glucocorticoids (GCs) prevent GO development or progression following RAI treatment [86], hence are recommended to be administered as prophylaxis for mild active $\mathrm{GO}$ when treated with RAI when there are risk factors for GO deterioration but can be considered even when these risk factors are absent if there is no strong contraindication to their use. The European Group for Graves' Orbitopathy (EUGOGO) guidelines recommend that oral prednisone prophylaxis, starting with a daily dose of $0.3-0.5 \mathrm{mg}$ prednisone/ $\mathrm{kg}$ body weight, be given in RAI treated patients at high risk of progression or de novo development of GO, and lower-dose prednisone $(0.2-0.3 \mathrm{mg} / \mathrm{kg}$ ) can be used in low risk patients [78]. Oral GCs can also be used in combination with other therapies discussed below when there is partial or no response to IV GCs in moderate-to-severe and active GO.

Intravenous (IV) GCs are the first line of treatment for moderate-to-severe and active GO as they are more effective than oral GCS in this group with a response rate of $80 \%$ for IV GCs compared to $50 \%$ for oral GCs [92]. This is preferably given IV as 12-weekly infusions that are more effective than daily infusions [93]. The currently used total dose is $4.5 \mathrm{~g}$ of methylprednisolone, with the higher dosage of $7.5 \mathrm{~g}$ being slightly more effective albeit with greater toxicity [94]. Bartalena et al. showed that those who deteriorate at 6 weeks after IV GCs are unlikely to benefit from continuing IV GCs as $63 \%$ and $53 \%$ remained in the same GO category at 12 and 24 weeks respectively [95]. In the same study, the patients who were unresponsive at 6 weeks eventually improved in $28 \%$ of cases for composite GO index, $58 \%$ for CAS and $32 \%$ for quality of life, suggesting that this group still has a significant possibility of improvement later [95]. Accordingly, IV GCs may be continued if the patient tolerates, and in some cases a second round of methylprednisolone has been utilized with notable benefits though one has to be aware that increasing total GC dose increases the risk of adverse effects [96]. The cumulative dose of methylprednisolone should not exceed 8 gram $[94,97]$, and it is essential to monitor these patients for potential adverse effects of GCs (liver dysfunction, metabolic changes, cardiac and cerebrovascular complications). Therapy should be withdrawn when the risk of adverse effects outweighs the benefits. In that case, an alternative strategy is to stop IV GCs and switch to a second-line treatment such as orbital decompression if required urgently; a combination of oral GCs and orbital radiotherapy; or enrollment in clinical trials for investigational therapies. 


\section{Orbital radiotherapy}

While not all studies have found this therapy beneficial, a systematic review on the topic [98] has identified orbital radiation to be effective in improving diplopia and GO severity [99, 100], and also in potentiating the effect of oral GCs [101]. It has overall a good safety record though radiation retinopathy remains a risk in these patients, particularly for diabetics which should therefore not be considered for this approach [102]. Technical details are essential in this area, and for a more in depth review we recommend the publications by Hahn et al. [103] and Matthiesen et al. [104].

\section{Cyclosporine}

Cyclosporine is a mainstay drug in transplantation medicine. Its mechanism of action relies on blocking IL-2 secretion from T cells through inhibition of calcineurin. After enthusiastic results in case series, a couple studies have documented that this agent is not effective as monotherapy in $\mathrm{GO}$; however in combination with oral GCs, it has been shown to be more effective than either treatment alone in moderate-to-severe and active $\mathrm{GO}$ in terms of better ocular outcome and lower recurrence of GO $[105,106]$. The most common adverse effects related to cyclosporine are dose-dependent liver and renal toxicities, gingival hyperplasia, non-significant increase in serum creatinine levels [106], and transient rise in blood pressure [105]. Hence, cyclosporine in combination with oral GCs can be considered as the next step when there is partial or no response to IV GCs in moderate-to-severe and active GO.

\section{Orbital surgery}

There are a number of surgical interventions that are employed in $\mathrm{GO}$ individuals. It is important to remember that their main role is rehabilitative; hence they should be performed in the inactive phase of the disease. However, in rapidly progressive active disease of at least moderate severity where immunomodulatory therapy has failed, it is sometimes appropriate to consider orbital decompression. Orbital decompression is occasionally used as first-line therapy for DON but most commonly in the cases that have failed IV GCs. The effect of orbital decompression has been shown also on the molecular level, with high hypoxia-inducible factor-1 (HIF-1) expression in orbital fat samples of patients retrieved during orbital decompression [107]. When decompression surgery is done for rehabilitative purposes, or if it is decided that it is not needed in that particular case, extraocular muscle surgery is the next step, and eyelid correction surgery comes last during the rehabilitative phase of therapy. Restorative eye surgery should be performed in the inactive stage of $\mathrm{GO}$, in order to prevent further deterioration post-surgery. The specifics of these surgeries are not the focus of this review but a number of good chapters and reviews are readily available [108-111].

\section{Azathioprine}

Azathioprine is an immuno-suppressive and anti-proliferative drug that has been used as a steroid sparing agent in other conditions. It has not demonstrated benefit as monotherapy in GO [112]. When used in combination with glucocorticoids, post-hoc analysis of an RCT demonstrated that those who completed treatment with azathioprine had improved clinical outcome at 48 weeks [113]. This suggests a potential role of azathioprine for prevent long term GO relapse of after steroids are discontinued.

\section{Botulinum toxin injection}

Due to its ability to interfere with muscle contractions, botulinum toxin $A$ has been studied in $\mathrm{GO}$ with the aim of decreasing the upper eyelid retraction. A few small studies [114-116] have reported on that outcome which seems to be positive but of small clinical magnitude and short in duration.

\section{Graves' Ophthalmopathy: Potential Future Options}

Over the past decade, a number of new treatment options have been explored for GO therapy. The vast majority of them have focused on immunomodulatory therapy, mainly alone but occasionally combined with orbital radiotherapy or thyroidectomy. Given the autoimmune nature of the disease, we will focus mainly on the immunomodulatory interventions which are more likely to influence disease pathogenesis as well as to further educate us on the evolving paradigm of GO development. It is noteworthy that GO is mild in majority of cases, and only $5 \%$ of these patients have moderate-to-severe disease [117] that would be a potential target for systemic immunotherapy. Attempts at reversing this degree of disease are described below, while the management of mild disease is mainly includes controlling risk factors, aggressive lubrication and selenium in active GO. One has to be aware of reporting bias in favor of positive studies, thus a number of therapies might appear extremely rewarding in the early phases of evaluation only to have the results dampened significantly as more controlled studies and multicenter trials take place.

\section{Rituximab}

Rituximab (RTX) is a humanized chimeric monoclonal antibody directed against the $C D 20$ complex present on the surface of $B$ cells. It induces a transient depletion of these cells, from pre-B lymphocytes to mature B cells, thus making it useful in B-cell lymphomas. The expectation in autoimmune diseases is that it might impact pathogenic antibody production along with minimizing B cells ability for antigen presentation and secretion of pro-inflammatory cytokines. It is currently approved for clinical use in rheumatoid arthritis and ANCA vasculitis. With respect to GO, it has been tested in a number of open label series [118] with encouraging results, and this has led to completion of 2 randomized clinical trials (RCT). One single-blind trial compared RTX with IV GCs in active and moderate-to-severe GO and concluded that it is a disease modifying drug as it inactivated GO in $100 \%$ and led to improvement in QOL in $38-62 \%$ of patients at 24 weeks [119]. In contrast, a double-blind RCT that compared RTX to placebo in the same type of GO population found that the drug did not perform better than its comparator; more so, the rate of adverse events with RTX was not negligible being reported in 26/28 treated patients [120]. Particularly notable was the development of DON as well as minor infections. This indicates that rituximab might have a propensity to lead to DON; hence patients at high risk for this outcome should not be offered 
this approach. The suggested mechanism for this process might be a rapid increase in orbital edema due to massive lysis of intra-orbital B cells [121]. Based on available data, it is best to consider retesting RTX in a multicenter RCT targeting therapy-refractory active and moderate-to-severe GO that is $<12$ months in duration and at relatively low risk for DON, in order to define the role that this agent can play in GO management.

\section{Tocilizumab}

Tocilizumab (TCZ) is a recombinant humanized monoclonal antibody against the IL- 6 receptor which has been explored in a few open label series as well as a placebo-controlled RCT. The rationale for the use of this agent relates to the significant increase in IL-6 levels in the active phase of $\mathrm{GO}$ in response to infiltration of orbits with activated T-helper- 1 cells. The subsequent release of cytokines by these cells leads to increased glycosaminoglycan production and adipogenesis, along with potentiation of the inflammatory cascade in the contained orbital environment. The largest case series is that of Perez-Moreiras JV et al. [122]. They treated 18 patients and reported impressive results with impact on both disease activity (mean CAS decrease was 5.9 points) and disease severity with a mean reduction in proptosis of $3.9 \mathrm{~mm}$ in $13 / 18$ patients, and improvement in extraocular motility in $15 / 18$ patients. The decrease in TSI by $76 \%$ was also remarkable while all this was achieved without development of any severe side-effects. All these patients had previously failed methylprednisolone therapy and some patients were treated more than a year after onset of GO, so it appears that this agent has the potential to rescue such patients if these results are confirmed. Despite these impressive results, the TCZ placebo-controlled RCT (ClinicalTrials.gov Identifier: NCT01297699) completed more than a year ago has not published its results, raising some doubts about the reproducibility of these results.

\section{Teprotumumab}

In recent years, there has been accumulating evidence that insulin-like growth factor-1 receptor (IGF1r) plays a role in GO pathophysiology $[123,124]$. While the presence of IGF1 $r$ autoantibodies remains debated $[123,125]$, it is apparent that stimulating or blocking IGF1 $\mathrm{r}$ is able to modulate the response triggered by the stimulation of $\mathrm{TSHr}$, and it appears that the two pathways can augment or inhibit each other in their intracellular signaling. Therefore, it is no surprise that a drug able to block the IGF1r was tried in GO therapy. Teprotumumab is such a compound and was developed for cancer therapy but did not prove sufficiently effective in that area. It is an IGF1 $r$ blocking antibody that blocks the action of both IGF-1 and TSH in fibrocytes [126]. It was tested in a multicenter fashion for the treatment of active and moderate-to-severe GO [123]. This double-masked trial randomized patients to active drug versus placebo and enrolled 88 patients that were evaluated based on a primary outcome of $\geq 2$ points reduction in CAS and a reduction in proptosis of $\geq 2 \mathrm{~mm}$ at 24 weeks ( 8 infusions every 3 weeks). The results of the intervention were noted rapidly (mostly between 6 and 12 weeks) and impacted both disease activity, with a decrease in CAS of 3.4 points ( $\pm 0.2 \mathrm{SD}$ ), and disease severity with a reduction in proptosis of $2.5 \mathrm{~mm}( \pm 0.2 \mathrm{SD})$. These are the most impressive results noted with a pharmacological agent in $\mathrm{GO}$ in an RCT, almost similar to the results obtained from one wall orbital decompression [127]. Overall, there were $69 \%$ of patients that reached the combined primary outcome in the teprotumumab group versus $20 \%$ in the placebo group ( $p<0.001)$. Additionally, benefit was noted regarding diplopia and quality of life. Hyperglycemia was the only consistently noted adverse event in the teprotumumab group. Diarrhea and mental confusion were the only 2 serious adverse events described as possibly related to teprotumumab. Given these overall impressive findings, a 2nd RCT is currently underway, with the primary outcome being reduction in proptosis. This trial is expected to be completed in June 2020 .

\section{Intravenous immunoglobulin}

This had promising initial results but was abandoned due to difficult logistics and uncertainty [128]. A trial reported good results [129] yet over the last 2 decades no additional reports have surfaced.

\section{TNF-alpha inhibition}

There are 2 blockers of TNF-alpha action that have been used in GO, namely etanercept (brand name Enbrel) and adalimumab (brand name Humira). They are being considered due to the evidence that TNF alpha cytokine production is increased early in GO pathogenesis given the dominant Th1 response at that disease stage. Both agents have been reported to have benefit in the inflammatory manifestations of $\mathrm{GO}$ (6/10 patients responded to etanercept [130] and 5/10 responded to adalimumab [131]) yet no consistent benefits were noted in disease severity. This is interesting as TNF alpha mRNA expression is fairly similar between active and inactive $\mathrm{GO}$ cases. At this point, there does not seem to be any registered trial exploring any of the TNF alpha blockers in a randomized fashion.

\section{Mycophenolate mofetil}

Mycophenolate mofetil (MMF) is a selective immunosuppressant used widely in many autoimmune diseases. Its mechanism of action relates to inhibition of inosine monophosphate dehydrogenase thus depleting guanosine nucleotides from target cells, preferentially $T$ and $B$ cells. This leads to the desired immune suppression. This approach was tested in active and moderate-to-severe $\mathrm{GO}$ patients in an RCT where overall clinical improvement was reported in $93 \%$ of those treated with MMF versus $71 \%$ in the GC group in [132]. In addition the MMF group had significantly higher rate and magnitude of improvement in the rate of diplopia and degree of proptosis than patients treated with glucocorticoids at the 24th week (90.4\% and 68.8\% improved, respectively) [132], suggesting that compared with GC treatment, MMF may be more effective and safer for patients with active and moderate-to-severe $\mathrm{GO}$. A second trial has then tested the possible additive effect between MMF and glucocorticoids. In this trial Kahaly et al. [133] compared MMF plus IV GC versus IV GC alone and found that at 12 weeks the two treatments were not different in their overall rate of response, neither was the relapse rate at 24 and 36 weeks. However, on post-hoc analysis classifying patients into 3 ordered categories, a benefit was detected for the combinations therapy at both 24 and 36 weeks. Side-effects were more numerous in the combination group but none led to discontinuation from the trial. 
Overall, these data are somewhat puzzling with significantly different response rate between the MMF arms in the 2 trials, much higher in the MMF alone intervention trial. None of the trials was double-blind, the single intervention trial not having any blinding listed while the combination MMF + GC trial being only single blind, with the patients and treating endocrinologists aware of trial assignment while the evaluating ophthalmologist was masked to the randomization. Ideally, a multicenter trial evaluating the impact of MMF in a double blind manner in comparison with placebo would be carried out in the future to understand the potential for efficacy with this agent.

\section{Thyroidectomy}

Removal of the thyroid gland has been proposed for a number of years as a modality of improving $\mathrm{GO}$ by eliminating the major source of the antigenic stimulation and thus hopefully decreasing TRAb. The work by Laurberg at al. [8] has supported the concept that TRAb titers decline fairly soon after thyroidectomy but a surgical study [134] looking at the impact of various surgical approaches on GO outcome failed to find that total thyroidectomy is more advantageous than subtotal thyroidectomy in this respect, thus arguing that the amount of thyroid tissue (i. e., degree of antigenic stimulation) might be less consequential than expected. Along the same line, early work by Tallstedt et al. [83] and Marcocci et al. [135] identified ATD and thyroidectomy as relatively identical regarding the risk of new or worse $\mathrm{GO}$, while a higher risk for this outcome was noted after RAI therapy (33\%). More recently, a case-control study by Meyer et al. [136] suggested that thyroidectomy performed in cases with low likelihood of achieving remission on ATD therapy has the potential to lead to earlier inactivation of $\mathrm{GO}$ and a more significant decline in CAS than ATD therapy. Even better results were obtained in a series reported by De Bellis et al. [87] which identified improvements in both severity and activity with thyroidectomy compared to ATD therapy. Whether addition of RAI therapy post thyroidectomy might improve GO outcome has also been tested, and a long term follow-up [137] suggests that while it might shorten the time to best GO outcome, the use of additional therapies for $\mathrm{GO}$ and the end result were the same between the groups. Taken together, these results do not support thyroidectomy as a preferred therapy for GD cases complicated with GO. Rather, they suggest that in moderate-to-severe and active GO cases where the likelihood of complete GD remission on ATD therapy is low, it is reasonable to consider thyroidectomy as long as available surgical expertise decreases the risk of operative complications.

\section{Therapy for dysthyroid optic neuropathy}

DON is currently a sight-threatening manifestation of GO, that is managed with IV methylprednisolone followed by decompressive surgery in resistant cases. However, that may not lead to $100 \%$ response rate; hence a number of case reports have described experience with other immunomodulatory agents in such cases. A TNF $\alpha$-blocker, infliximab, has been employed in one such case and noted positive results [138]. TCZ was used in 2 DON cases: one DON case was included in the initial cohort reported by Moreiras-Perez et al. [122] and another one was reported by Pascual-Camps et al. [139] very recently. In both cases, TCZ therapy was deemed successful. RTX has been employed in a few cases of DON, and it has been associated with transient [119] or sustained DON development in a few cases $[120,140,141]$. While in others, RTX has reportedly led to improvement in DON [118]. We believe that this agent can pose significant risk for this category of patients and for those with high propensity to progress to DON; hence it should be avoided in these patients. It is likely that advances in this area will follow the overall approach in GO since the small number of DON cases ( $5 \%$ of cases of moderate-to-severe GO) make an RCT dedicated specifically to DON impractical.

\section{Conclusions}

Current therapeutic preferences in GD are shifting towards ATD. There is very strong evidence that long term ATD therapy is a safe and effective option for select GD subgroups. In addition, new GD therapies are (slowly) emerging, focusing on immunomodulation. The advances in technology are also opening doors to non-pharmaceutical interventions that aim to deal with both structural abnormalities posed by nodules as well as with biochemical abnormalities of hyperthyroidism.

In the treatment of $\mathrm{GO}$, a number of new approaches (immunotherapy) and some old pathways (thyroidectomy) are being tested and retested, and so far the most promising data seem to be reported in the tocilizumab and teprotumumab trials. It will also be likely that agents identified as beneficial in GD management will be tested in $\mathrm{GO}$ as well. A number of these trials have not been double-blind in their design, hence it is pertinent to consider that a subjective measurement may be part of the outcome in many of them. It is also noteworthy that the trials including placebo as one of the arms reported consistent improvement in that group as well. This demonstrates the importance of considering the natural history of the disease when designing clinical trials for GO.

In the coming years, our main clinical responsibility will be to find the proper balance between the benefits and potential risks of these incoming therapies, and to identify the subgroups of patients where this ratio is most likely to favor a safe and successful therapeutic outcome.

\section{Conflict of Interest}

The authors declare that they have no conflict of interest.

\section{References}

[1] Bartley GB. The epidemiologic characteristics and clinical course of ophthalmopathy associated with autoimmune thyroid disease in Olmsted County, Minnesota. Trans Am Ophthalmol Soc 1994; 92: 477-588

[2] Wiersinga WM, Smit T, van der Gaag R, Koornneef L. Temporal relationship between onset of Graves' ophthalmopathy and onset of thyroidal Graves' disease. J Endocrinol Invest 1988; 11: 615-619

[3] Ross DS, Burch HB, Cooper DS, Greenlee MC, Laurberg P, Maia AL, Rivkees SA, Samuels M, Sosa JA, Stan MN, Walter MA. 2016 American Thyroid Association Guidelines for Diagnosis and Management of Hyperthyroidism and Other Causes of Thyrotoxicosis. Thyroid 2016; 26: 1343-1421 
[4] Burch HB, Burman KD, Cooper DS. A 2011 survey of clinical practice patterns in the management of Graves' disease. J Clin Endocrinol Metab 2012; 97: 4549-4558

[5] Bartalena L, Burch HB, Burman KD, Kahaly G]. A 2013 European survey of clinical practice patterns in the management of Graves' disease. Clin Endocrinol 2016; 84: 115-120

[6] Brito JP, Schilz S, Singh Ospina N, Rodriguez-Gutierrez R, Maraka S, Sangaralingham LR, Montori VM. Antithyroid Drugs-The most common treatment for graves' disease in the United States: A nationwide population-based study. Thyroid 2016; 26: 1144-1145

[7] Sundaresh V, Brito JP, Thapa P, Bahn RS, Stan MN. Comparative effectiveness of treatment choices for graves' hyperthyroidism: A historical cohort study. Thyroid 2017; 27: 497-505

[8] Laurberg P, Wallin G, Tallstedt L, Abraham-Nordling M, Lundell G, Torring O. TSH-receptor autoimmunity in Graves' disease after therapy with anti-thyroid drugs, surgery, or radioiodine: A 5-year prospective randomized study. Eur J Endocrinol 2008; 158: 69-75

[9] Burch HB, Solomon BL, Cooper DS, Ferguson P, Walpert N, Howard R. The effect of antithyroid drug pretreatment on acute changes in thyroid hormone levels after (131)I ablation for Graves' disease. J Clin Endocrinol Metab 2001; 86: 3016-3021

[10] Akamizu T, Satoh T, Isozaki O, Suzuki A, Wakino S, Iburi T, Tsuboi K, Monden T, Kouki T, Otani H, Teramukai S, Uehara R, Nakamura Y, Nagai M, Mori M. Diagnostic criteria, clinical features, and incidence of thyroid storm based on nationwide surveys. Thyroid 2012; 22: 661-679

[11] de Rooij A, Vandenbroucke JP, Smit JW, Stokkel MP, Dekkers OM. Clinical outcomes after estimated versus calculated activity of radioiodine for the treatment of hyperthyroidism: Systematic review and meta-analysis. Eur J Endocrinol 2009; 161: 771-777

[12] Canto AU, Dominguez PN, Jimeno CA, Obaldo JM, Ogbac RV. Comparison of fixed versus calculated activity of radioiodine for the treatment of graves disease in adults. Endocrinol Metab 2016; 31: 168-173

[13] Bonnema S], Bennedbaek FN, Gram J, Veje A, Marving ], Hegedus L. Resumption of methimazole after 131 l therapy of hyperthyroid diseases: Effect on thyroid function and volume evaluated by a randomized clinical trial. Eur J Endocrinol 2003; 149: 485-492

[14] Hieu TT, Russell AW, Cuneo R, Clark J, Kron T, Hall P, Doi SA. Cancer risk after medical exposure to radioactive iodine in benign thyroid diseases: A meta-analysis. Endocr Relat Cancer 2012; 19: 645-655

[15] Stan MN, Durski JM, Brito JP, Bhagra S, Thapa P, Bahn RS. Cohort study on radioactive iodine-induced hypothyroidism: Implications for Graves' ophthalmopathy and optimal timing for thyroid hormone assessment. Thyroid 2013; 23: 620-625

[16] Erbil Y, Ozluk Y, Giris M, Salmaslioglu A, Issever H, Barbaros U, Kapran Y, Ozarmagan S, Tezelman S. Effect of lugol solution on thyroid gland blood flow and microvessel density in the patients with Graves' disease. J Clin Endocrinol Metab 2007; 92: 2182-2189

[17] Yang Y, Hwang S, Kim M, Lim Y, Kim MH, Lee S, Lim D], Kang MI, Cha BY. Refractory graves' disease successfully cured by adjunctive cholestyramine and subsequent total thyroidectomy. Endocrinol Metab (Seoul, Korea) 2015; 30: 620-625

[18] Edafe O, Antakia R, Laskar N, Uttley L, Balasubramanian SP. Systematic review and meta-analysis of predictors of post-thyroidectomy hypocalcaemia. Br J Surg 2014; 101: 307-320

[19] Adam MA, Thomas S, Youngwirth L, Hyslop T, Reed SD, Scheri RP, Roman SA, Sosa JA. Is There a Minimum Number of Thyroidectomies a Surgeon Should Perform to Optimize Patient Outcomes? Ann Surg 2017; 265: 402-407

[20] Rubio GA, Koru-Sengul T, Vaghaiwalla TM, Parikh PP, Farra JC, Lew JI. Postoperative Outcomes in Graves' Disease Patients: Results from the Nationwide Inpatient Sample Database. Thyroid 2017; 27: 825-831
[21] Noordzij JP, Lee SL, Bernet V], Payne RJ, Cohen SM, McLeod IK, Hier MP, Black MJ, Kerr PD, Richards ML, Lo CY, Raffaelli M, Bellantone R, Lombardi CP, Cohen JI, Dietrich MS. Early prediction of hypocalcemia after thyroidectomy using parathyroid hormone: an analysis of pooled individual patient data from nine observational studies. J Am Coll Surg 2007; 205: 748-754

[22] Promberger R, Ott J, Kober F, Karik M, Freissmuth M, Hermann M. Normal parathyroid hormone levels do not exclude permanent hypoparathyroidism after thyroidectomy. Thyroid 2011; 21: 145-150

[23] Annerbo M, Hultin H, Stalberg P, Hellman P. Left-shifted relation between calcium and parathyroid hormone in Graves' disease. I Clin Endocrinol Metab 2014; 99: 545-551

[24] Shah M, Bancos I, Thompson GB, Richards ML, Kasperbauer JL, Clarke BL, Drake MT, Stan MN. Teriparatide therapy and reduced postoperative hospitalization for postsurgical hypoparathyroidism. JAMA Otolaryngol Head Neck Surg 2015; 141: 822-827

[25] Cooper DS. Antithyroid drugs. N Eng J Med 2005; 352: 905-917

[26] Laurberg P. Remission of Graves' disease during anti-thyroid drug therapy. Time to reconsider the mechanism? Eur J Endocrinol 2006; 155: 783-786

[27] Vaidya B, Wright A, Shuttleworth ], Donohoe M, Warren R, Brooke A Gericke CA, Ukoumunne OC. Block \& replace regime versus titration regime of antithyroid drugs for the treatment of Graves' disease: A retrospective observational study. Clin Endocrinol (Oxf) 2014; 81: 610-613

[28] Carella C, Mazziotti G, Sorvillo F, Piscopo M, Cioffi M, Pilla P, Nersita R, lorio S, Amato G, Braverman LE, Roti E. Serum thyrotropin receptor antibodies concentrations in patients with Graves' disease before, at the end of methimazole treatment, and after drug withdrawal: evidence that the activity of thyrotropin receptor antibody and/or thyroid response modify during the observation period. Thyroid 2006; 16: 295-302

[29] Schott M, Eckstein A, Willenberg HS, Nguyen TB, Morgenthaler NG, Scherbaum WA. Improved prediction of relapse of Graves' thyrotoxicosis by combined determination of TSH receptor and thyroperoxidase antibodies. Horm Metab Res 2007; 39: 56-61

[30] Mazza E, Carlini M, Flecchia D, Blatto A, Zuccarini O, Gamba S, Beninati S, Messina M. Long-term follow-up of patients with hyperthyroidism due to Graves' disease treated with methimazole. Comparison of usual treatment schedule with drug discontinuation vs continuous treatment with low methimazole doses: a retrospective study. J Endocrinol Invest 2008; 31: 866-872

[31] Konishi T, Okamoto Y, Ueda M, Fukuda Y, Harusato I, Tsukamoto Y, Hamada N. Drug discontinuation after treatment with minimum maintenance dose of an antithyroid drug in Graves' disease: A retrospective study on effects of treatment duration with minimum maintenance dose on lasting remission. Endocr J 2011; 58: 95-100

[32] Eckstein AK, Lax H, Losch C, Glowacka D, Plicht M, Mann K, Esser ], Morgenthaler NG. Patients with severe Graves' ophthalmopathy have a higher risk of relapsing hyperthyroidism and are unlikely to remain in remission. Clin Endocrinol (Oxf) 2007; 67: 607-612

[33] Azizi F, Ataie L, Hedayati M, Mehrabi Y, Sheikholeslami F. Effect of long-term continuous methimazole treatment of hyperthyroidism: Comparison with radioiodine. Eur J Endocrinol 2005; 152: 695-701

[34] Azizi F, Malboosbaf R. Long-term antithyroid drug treatment: A systematic review and meta-analysis. Thyroid 2017; 27: 1223-1231

[35] Villagelin D, Romaldini JH, Santos RB, Milkos AB, Ward LS. Outcomes in relapsed graves' disease patients following radioiodine or prolonged low dose of methimazole treatment. Thyroid 2015; 25: 1282-1290

[36] Kim YA, Cho SW, Choi HS, Moon S, Moon JH, Kim KW, Park DJ, Yi KH, Park Y], Cho BY. The Second Antithyroid Drug Treatment Is Effective in Relapsed Graves' Disease Patients: A Median 11-Year Follow-Up Study. Thyroid 2017; 27: 491-496 
[37] Andersohn F, Konzen C, Garbe E. Systematic review: Agranulocytosis induced by nonchemotherapy drugs. Ann Int Med 2007; 146: 657-665

[38] Takata K, Kubota S, Fukata S, Kudo T, Nishihara E, Ito M, Amino N, Miyauchi A. Methimazole-induced agranulocytosis in patients with Graves' disease is more frequent with an initial dose of $30 \mathrm{mg}$ daily than with $15 \mathrm{mg}$ daily. Thyroid 2009; 19: 559-563

[39] Chen PL, Shih SR, Wang PW, Lin YC, Chu CC, Lin JH, Chen SC, Chang CC, Huang TS, Tsai KS, Tseng FY, Wang CY, Lu JY, Chiu WY, Chang CC, Chen YH, Chen YT, Fann CS, Yang WS, Chang TC. Genetic determinants of antithyroid drug-induced agranulocytosis by human leukocyte antigen genotyping and genome-wide association study. Nat Commun 2015; 6: 7633

[40] Hallberg P, Eriksson N, Ibanez L, Bondon-Guitton E, Kreutz R, Carvajal A, Lucena MI, Ponce ES, Molokhia M, Martin J, Axelsson T, Yue QY, Magnusson PK, Wadelius M. Genetic variants associated with antithyroid drug-induced agranulocytosis: A genome-wide association study in a European population. Lancet Diabetes Endocrinol 2016; 4: 507-516

[41] Vilchez FJ, Torres I, Garcia-Valero A, Lopez-Tinoco C, de Los Santos A, Aguilar-Diosdado M. Concomitant agranulocytosis and hepatotoxicity after treatment with carbimazole. Ann Pharmacother 2006; 40: 2059-2063

[42] Ruiz JK, Rossi GV, Vallejos HA, Brenet RW, Lopez IB, Escribano AA. Fulminant hepatic failure associated with propylthiouracil. Ann Pharmacother 2003; 37: 224-228

[43] Bahn RS, Burch HS, Cooper DS, Garber JR, Greenlee CM, Klein IL, Laurberg P, McDougall IR, Rivkees SA, Ross D, Sosa JA, Stan MN. The role of propylthiouracil in the management of graves' disease in adults: Report of a meeting jointly sponsored by the American Thyroid Association and the Food and Drug Administration. Thyroid 2009; 19: 673-674

[44] Yang J, Li LF, Xu Q, Zhang J, Weng WW, Zhu Y], Dong MJ. Analysis of 90 cases of antithyroid drug-induced severe hepatotoxicity over 13 years in China. Thyroid 2015; 25: 278-283

[45] Andersen SL, Olsen J, Laurberg P. Antithyroid Drug Side Effects in the Population and in Pregnancy. The Journal of clinical endocrinology and metabolism 2016; 101: 1606-1614

[46] Wang R, Tan J, Zhang G, Zheng W, Li C. Risk factors of hepatic dysfunction in patients with Graves' hyperthyroidism and the efficacy of 131iodine treatment. Medicine 2017; 96: e6035

[47] Gunton JE, Stiel J, Clifton-Bligh P, Wilmshurst E, McElduff A. Prevalence of positive anti-neutrophil cytoplasmic antibody (ANCA) in patients receiving anti-thyroid medication. Eur J Endocrinol 2000; 142: 587

[48] Yang J, Yao LP, Dong MJ, Xu Q, Zhang J, Weng WW, Chen F. Clinical characteristics and outcomes of propylthiouracil-induced antineutrophil cytoplasmic antibody-associated vasculitis in patients with graves' disease: A median 38-month retrospective cohort study from a single institution in China. Thyroid 2017; 27: 1469-1474

[49] Kubota S. Successful Re-administration of Low-dose of Methimazole (MMI) in Graves' Disease Patients Who Experienced Allergic Cutaneous Reactions to MMI at Initial Treatment and Had Received Long-term Propylthiouracil (PTU). Int Med (Tokyo, Japan) 2016; 55: 3235-3237

[50] Vrca VB, Mayer L, Skreb F, Rahelic D, Marusic S. Antioxidant supplementation and serum lipids in patients with Graves' disease: Effect on LDL-cholesterol. Acta Pharm (Zagreb, Croatia) 2012; 62: 115-122

[51] Wang L, Wang B, Chen SR, Hou X, Wang XF, Zhao SH, Song JQ, Wang YG. Effect of Selenium Supplementation on Recurrent Hyperthyroidism Caused by Graves' Disease: A prospective pilot study. Horm Metab Res 2016; 48: 559-564
[52] Leo M, Bartalena L, Rotondo Dottore G, Piantanida E, Premoli P, Ionni I, Di Cera M, Masiello E, Sassi L, Tanda ML, Latrofa F, Vitti P, Marcocci C, Marino M. Effects of selenium on short-term control of hyperthyroidism due to Graves' disease treated with methimazole: results of a randomized clinical trial. J Endocrinol Invest 2017; 40: 281-287

[53] Calissendorff], Mikulski E, Larsen EH, Moller M. A Prospective Investigation of Graves' Disease and Selenium: Thyroid Hormones, Auto-Antibodies and Self-Rated Symptoms. Eur Thyroid J 2015; 4: 93-98

[54] Kahaly G], RiedI M, Konig J, Diana T, Schomburg L. Double-Blind, Placebo-Controlled, Randomized Trial of Selenium in Graves Hyperthyroidism. J Clin Endocrinol Metab 2017; 102: 4333-4341

[55] Bogazzi F, Bartalena L, Campomori A, Brogioni S, Traino C, De Martino F, Rossi G, Lippi F, Pinchera A, Martino E. Treatment with lithium prevents serum thyroid hormone increase after thionamide withdrawal and radioiodine therapy in patients with Graves' disease. J Clin Endocrinol Metab 2002; 87: 4490-4495

[56] Hammond EN, Vangu MD. Effect of adjuvant lithium on thyroxine (T4) concentration after radioactive iodine therapy. Eur ] Nucl Med Mol Imag 2016; 43: 1980-1987

[57] Prakash I, Nylen ES, Sen S. Lithium as an alternative option in Graves thyrotoxicosis. Case Rep Endocrinol 2015; 2015: 86934

[58] Sato S, Noh JY, Sato S, Suzuki M, Yasuda S, Matsumoto M, Kunii Y, Mukasa K, Sugino K, Ito K, Nagataki S, Taniyama M. Comparison of efficacy and adverse effects between methimazole $15 \mathrm{mg}+$ inorganic iodine $38 \mathrm{mg} /$ day and methimazole $30 \mathrm{mg} /$ day as initial therapy for Graves' disease patients with moderate to severe hyperthyroidism. Thyroid 2015; 25: 43-50

[59] Okamura K, Sato K, Fujikawa M, Bandai S, Ikenoue H, Kitazono T. Remission after potassium iodide therapy in patients with Graves' hyperthyroidism exhibiting thionamide-associated side effects. J Clin Endocrinol Metab 2014; 99: 3995-4002

[60] Jha S, Waghdhare S, Reddi R, Bhattacharya P. Thyroid storm due to inappropriate administration of a compounded thyroid hormone preparation successfully treated with plasmapheresis. Thyroid 2012; 22: $1283-1286$

[61] Muller C, Perrin P, Faller B, Richter S, Chantrel F. Role of plasma exchange in the thyroid storm. Therap Apheresis Dial 2011; 15: 522-531

[62] Chopra I], Williams DE, Orgiazzi ], Solomon DH. Opposite effects of dexamethasone on serum concentrations of 3,3',5'-triiodothyronine (reverse T3) and 3,3'5-triiodothyronine (T3). J Clin Endocrinol Metab 1975; 41: 911-920

[63] Cooper DS, Laurberg P. Hyperthyroidism in pregnancy. Lancet Diabetes Endocrinol 2013; 1: 238-249

[64] Alexander EK, Pearce EN, Brent GA, Brown RS, Chen H, Dosiou C, Grobman WA, Laurberg P, Lazarus JH, Mandel S], Peeters RP, Sullivan S. 2017 Guidelines of the American Thyroid Association for the Diagnosis and Management of Thyroid Disease During Pregnancy and the Postpartum. Thyroid 2017; 27: 315-389

[65] Andersen SL, Olsen J, Wu CS, Laurberg P. Birth defects after early pregnancy use of antithyroid drugs: A Danish nationwide study. J Clin Endocrinol Metab 2013; 98: 4373-4381

[66] Laurberg P, Andersen SL. Therapy of endocrine disease: antithyroid drug use in early pregnancy and birth defects: Time windows of relative safety and high risk? Eur J Endocrinol 2014; 171: R13-R20

[67] Rotondi M, Capelli V, Coperchini F, Pinto S, Croce L, Tonacchera M, Chiovato L. Post partum and non-post partum relapsing Graves' hyperthyroidism display different response to anti-thyroid drugs. Eur J Endocrinol 2018; 178: 589-594

[68] El Fassi D, Nielsen CH, Bonnema S], Hasselbalch HC, Hegedus L. B lymphocyte depletion with the monoclonal antibody rituximab in Graves' disease: A controlled pilot study. J Clin Endocrinol Metab 2007; 92: 1769-1772 
[69] Nielsen CH, El Fassi D, Hasselbalch HC, Bendtzen K, Hegedus L. B-cell depletion with rituximab in the treatment of autoimmune diseases. Graves' ophthalmopathy the latest addition to an expanding family. Expert Opin Biol Ther 2007; 7: 1061-1078

[70] Dawson NAJ, Vent-Schmidt J, Levings MK. Engineered Tolerance: Tailoring Development, Function, and Antigen-Specificity of Regulatory T Cells. Front Immunol 2017; 8: 1460

[71] Sanders P, Young S, Sanders J, Kabelis K, Baker S, Sullivan A, Evans M, Clark J, Wilmot J, Hu X, Roberts E, Powell M, Nunez Miguel R, Furmaniak J, Rees Smith B. Crystal structure of the TSH receptor (TSHR) bound to a blocking-type TSHR autoantibody. J Mol Endocrinol 2011; 46: 81-99

[72] Furmaniak J, Sanders J, Young S, Kabelis K, Sanders P, Evans M, Clark J, Wilmot J, Rees Smith B. In vivo effects of a human thyroid-stimulating monoclonal autoantibody (M22) and a human thyroid-blocking autoantibody (K1-70). Auto Immun Highlights 2012; 3: 19-25

[73] Lang BH, Wu ALH. The efficacy and safety of high-intensity focused ultrasound ablation of benign thyroid nodules. Ultrasonography (Seoul, Korea) 2018; 37: 89-97

[74] Spiezia S, Garberoglio R, Milone F, Ramundo V, Caiazzo C, Assanti AP, Deandrea M, Limone PP, Macchia PE, Lombardi G, Colao A, Faggiano A. Thyroid nodules and related symptoms are stably controlled two years after radiofrequency thermal ablation. Thyroid 2009; 19: 219-225

[75] Faggiano A, Ramundo V, Assanti AP, Fonderico F, Macchia PE, Misso C, Marciello F, Marotta V, Del Prete M, Papini E, Lombardi G, Colao A, Spiezia S. Thyroid Nodules Treated with Percutaneous Radiofrequency Thermal Ablation: A Comparative Study. J Clin Endocrinol Metab 2012; 97: 4439-4445

[76] Baek JH, Moon WJ, Kim YS, Lee JH, Lee D. Radiofrequency ablation for the treatment of autonomously functioning thyroid nodules. World J Surg 2009; 33: 1971-1977

[77] Hamidi O, Callstrom MR, Lee RA, Dean D, Castro MR, Morris JC, Stan M. Outcomes of radiofrequency ablation therapy for large benign thyroid nodules: A mayo clinic case series. Mayo Clin Proc 2018; 93 : 1018-1025

[78] Bartalena L, Baldeschi L, Boboridis K, Eckstein A, Kahaly G], Marcocci C, Perros P, Salvi M, Wiersinga WM. The 2016 European Thyroid Association/European Group on Graves' Orbitopathy Guidelines for the Management of Graves' Orbitopathy. Eur Thyroid J 2016; 5: 9-26

[79] Stan MN, Garrity JA, Bahn RS. The evaluation and treatment of graves ophthalmopathy. Med Clin North Am 2012; 96: 311-328

[80] Prummel MF, Wiersinga WM. Smoking and risk of Graves' disease. JAMA 1993; 269: 479-482

[81] Eckstein A, Quadbeck B, Mueller G, Rettenmeier AW, Hoermann R, Mann K, Steuhl P, Esser J. Impact of smoking on the response to treatment of thyroid associated ophthalmopathy. $\mathrm{Br}$ J Ophthalmol 2003; 87: 773-776

[82] Pfeilschifter ], Ziegler R. Smoking and endocrine ophthalmopathy: Impact of smoking severity and current vs lifetime cigarette consumption. Clin Endocrinol (Oxf) 1996; 45: 477-481

[83] Tallstedt L, Lundell G, Torring O, Wallin G, Ljunggren JG, Blomgren H, Taube A. Occurrence of ophthalmopathy after treatment for Graves' hyperthyroidism. The Thyroid Study Group. N Eng J Med 1992; 326: 1733-1738

[84] Bartalena L, Marcocci C, Bogazzi F, Manetti L, Tanda ML, Dell'Unto E, Bruno-Bossio G, Nardi M, Bartolomei MP, Lepri A, Rossi G, Martino E, Pinchera A. Relation between therapy for hyperthyroidism and the course of Graves' ophthalmopathy. N Eng J Med 1998; 338: 73-78

[85] Traisk F, Tallstedt L, Abraham-Nordling M, Andersson T, Berg G, Calissendorff J, Hallengren B, Hedner P, Lantz M, Nystrom E, Ponjavic V, Taube A, Torring O, Wallin G, Asman P, Lundell G. Thyroid-associated ophthalmopathy after treatment for Graves' hyperthyroidism with antithyroid drugs or iodine-131. J Clin Endocrinol Metab 2009; 94: 3700-3707

[86] Shiber S, Stiebel-Kalish H, Shimon I, Grossman A, Robenshtok E. Glucocorticoid regimens for prevention of Graves' ophthalmopathy progression following radioiodine treatment: systematic review and meta-analysis. Thyroid 2014; 24: 1515-1523

[87] De Bellis A, Conzo G, Cennamo G, Pane E, Bellastella G, Colella C, lacovo AD, Paglionico VA, Sinisi AA, Wall JR, Bizzarro A, Bellastella A. Time course of Graves' ophthalmopathy after total thyroidectomy alone or followed by radioiodine therapy: A 2-year longitudinal study. Endocrine 2012; 41: 320-326

[88] Laurberg P, Berman DC, Andersen S, Pedersen IB. Sustained control of graves' hyperthyroidism during long-term low-dose antithyroid drug therapy of patients with severe graves' orbitopathy. Thyroid 2011; 21: 951-956

[89] Elbers L, Mourits M, Wiersinga W. Outcome of very long-term treatment with antithyroid drugs in Graves' hyperthyroidism associated with Graves' orbitopathy. Thyroid 2011; 21: 279-283

[90] Baudouin C, Cochener B, Pisella PJ, Girard B, Pouliquen P, Cooper H, Creuzot-Garcher C. Randomized, phase III study comparing osmoprotective carboxymethylcellulose with sodium hyaluronate in dry eye disease. Eur J Ophthalmol 2012; 22: 751-761

[91] Marcocci C, Kahaly G], Krassas GE, Bartalena L, Prummel M, Stahl M, Altea MA, Nardi M, Pitz S, Boboridis K, Sivelli P, von Arx G, Mourits MP, Baldeschi L, Bencivelli W, Wiersinga W. Selenium and the course of mild Graves' orbitopathy. N Eng J Med 2011; 364: 1920-1931

[92] Kahaly G], Pitz S, Hommel G, Dittmar M. Randomized, single blind trial of intravenous versus oral steroid monotherapy in Graves' orbitopathy. J Clin Endocrinol Metab 2005; 90: 5234-5240

[93] Zhu W, Ye L, Shen L, Jiao Q, Huang F, Han R, Zhang X, Wang S, Wang W, Ning $G$. A prospective, randomized trial of intravenous glucocorticoids therapy with different protocols for patients with graves' ophthalmopathy. J Clin Endocrinol Metab 2014; 99: 1999-2007

[94] Bartalena L, Krassas GE, Wiersinga W, Marcocci C, Salvi M, Daumerie C, Bournaud C, Stahl M, Sassi L, Veronesi G, Azzolini C, Boboridis KG, Mourits MP, Soeters MR, Baldeschi L, Nardi M, Curro N, Boschi A, Bernard M, von Arx G. Efficacy and safety of three different cumulative doses of intravenous methylprednisolone for moderate to severe and active Graves' orbitopathy. J Clin Endocrinol Metab 2012; 97: 4454-4463

[95] Bartalena L, Veronesi G, Krassas GE, Wiersinga WM, Marcocci C, Marino M, Salvi M, Daumerie C, Bournaud C, Stahl M, Sassi L, Azzolini C, Boboridis KG, Mourits MP, Soeters MR, Baldeschi L, Nardi M, Curro N, Boschi A, Bernard M, von Arx G, Perros P, Kahaly GJ. Does early response to intravenous glucocorticoids predict the final outcome in patients with moderate-to-severe and active Graves' orbitopathy? J Endocrinol Invest 2017; 40: 547-553

[96] Marcocci C, Watt T, Altea MA, Rasmussen AK, Feldt-Rasmussen U, Orgiazzi ], Bartalena L. Fatal and non-fatal adverse events of glucocorticoid therapy for Graves' orbitopathy: A questionnaire survey among members of the European Thyroid Association. Eur ] Endocrinol 2012; 166: 247-253

[97] Zang S, Ponto KA, Pitz S, Kahaly G]. Dose of intravenous steroids and therapy outcome in Graves' orbitopathy. J Endocrinol Invest 2011; 34: 876-880

[98] Bradley EA, Gower EW, Bradley DJ, Meyer DR, Cahill KV, Custer PL, Holck DE, Woog JJ. Orbital radiation for graves ophthalmopathy: A report by the American Academy of Ophthalmology. Ophthalmology 2008; 115: 398-409

[99] Prummel MF, Terwee CB, Gerding MN, Baldeschi L, Mourits MP, Blank L, Dekker FW, Wiersinga WM. A randomized controlled trial of orbital radiotherapy versus sham irradiation in patients with mild Graves' ophthalmopathy. J Clin Endocrinol Metab 2004; 89: 15-20 
[100] Oeverhaus M, Witteler T, Lax H, Esser ], Führer D, Eckstein A. Combination Therapy of Intravenous Steroids and Orbital Irradiation is More Effective Than Intravenous Steroids Alone in Patients with Graves' Orbitopathy. Horm Metab Res 2017; 49: 739-747

[101] Marcocci C, Bartalena L, Bogazzi F, Bruno-Bossio G, Lepri A, Pinchera A. Orbital radiotherapy combined with high dose systemic glucocorticoids for Graves' ophthalmopathy is more effective than radiotherapy alone: Results of a prospective randomized study. J Endocrinol Invest 1991; 14: 853-860

[102] Tanda ML, Bartalena L. Efficacy and safety of orbital radiotherapy for graves' orbitopathy. J Clin Endocrinol Metab 2012; 97: 3857-3865

[103] Hahn E, Laperriere N, Millar BA, Oestreicher J, McGowan H, Krema H, Gill H, DeAngelis D, Hurwitz J, Tucker N, Simpson R, Chung C. Orbital radiation therapy for Graves' ophthalmopathy: measuring clinical efficacy and impact. Pract Radiation. Oncol 2014; 4: 233-239

[104] Matthiesen C, Thompson JS, Thompson D, Farris B, Wilkes B, Ahmad S, Herman T, Bogardus C Jr.. The efficacy of radiation therapy in the treatment of Graves' orbitopathy. Int J Radiation Oncol Biol Phys 2012; 82: 117-123

[105] Prummel MF, Mourits MP, Berghout A, Krenning EP, van der Gaag R, Koornneef L, Wiersinga WM. Prednisone and cyclosporine in the treatment of severe Graves' ophthalmopathy. N Eng J Med 1989; 321: 1353-1359

[106] Kahaly G, Schrezenmeir ], Krause U, Schweikert B, Meuer S, Muller W, Dennebaum R, Beyer J. Ciclosporin and prednisone v. prednisone in treatment of Graves' ophthalmopathy: a controlled, randomized and prospective study. Eur J Clin Invest 1986; 16: 415-422

[107] Görtz G-E, Horstmann M, Aniol B, Reyes BD, Fandrey J, Eckstein A, Berchner-Pfannschmidt U. Hypoxia-Dependent HIF-1 Activation Impacts on Tissue Remodeling in Graves' Ophthalmopathy-Implications for Smoking. J Clin Endocrinol Metab 2016; 101: 4834-4842

[108] Garrity JA. Preoperative Assessment and Orbital Decompression Surgery in Patients with Graves' Ophthalmopathy. In: Bahn RS. (ed). Graves' Disease: A Comprehensive Guide for Clinicians. Berlin: Springer; 2015: 277-285

[109] Eckstein A, Joachim E. Surgical Management of Extraocular Muscle Dysfunction in Patients with GO. In: Bahn RS.(ed) Graves' Disease: A Comprehensive Guide for Clinicians. Berlin: Springer; 2016: 287-299

[110] Baldeschi L. Rehabilitative Surgery. In: Wiersinga WM, Kahaly G]. (eds) Graves' Orbitopathy: A Multidisciplinary Approach - Questions and Answers. 2 ed Basel: Karger; 2010: 167-170

[111] Baldeschi L. Orbital Decompression. In: Wiersinga WM, Kahaly G]. (eds). Graves' Orbitopathy: A Multidisciplinary Approach - Questions and Answers. 2 edBasel: Karger; 2010: 171-185

[112] Perros P, Weightman DR, Crombie AL, Kendall-Taylor P. Azathioprine in the treatment of thyroid-associated ophthalmopathy. Acta Endocrinol 1990; 122: 8-12

[113] Rajendram R, Taylor PN, Wilson V], Harris N, Morris OC, Tomlinson M, Yarrow S, Garrott H, Herbert HM, Dick AD, Cook A, Gattamaneni R, Jain R, Olver J, Hurel SJ, Bremner F, Drummond SR, Kemp E, Ritchie DM, Rumsey N, Morris D, Lane C, Palaniappan N, Li C, Pell J, Hills R, Ezra DG, Potts MJ, Jackson S, Rose GE, Plowman N, Bunce C, Uddin JM, Lee RWJ, Dayan CM. Combined immunosuppression and radiotherapy in thyroid eye disease (CIRTED): $A$ multicentre, $2 \times 2$ factorial, double-blind, randomised controlled trial. Lancet Diabetes Endocrinol 2018; 6: 299-309

[114] Grisolia ABD, Couso RC, Matayoshi S, Douglas RS, Briceno CA. Non-surgical treatment for eyelid retraction in thyroid eye disease (TED). Br J Ophthalmol 2017, doi:10.1136/bjophthalmol-2017-310695 [Epub ahead of print]

[115] Uddin JM, Davies PD. Treatment of upper eyelid retraction associated with thyroid eye disease with subconjunctival botulinum toxin injection. Ophthalmology 2002; 109: 1183-1187
[116] Morgenstern KE, Evanchan J, Foster JA, Cahill KV, Burns JA, Holck DE, Perry JD, Wulc AE. Botulinum toxin type a for dysthyroid upper eyelid retraction. Ophthal Plastic Reconstruct Surg 2004; 20: 181-185

[117] Laurberg P, Berman DC, Bulow Pedersen I, Andersen S, Carle A. Incidence and clinical presentation of moderate to severe graves' orbitopathy in a Danish population before and after iodine fortification of salt. J Clin Endocrinol Metab 2012; 97: 2325-2332

[118] Salvi M, Vannucchi G, Beck-Peccoz P. Potential utility of rituximab for Graves' orbitopathy. J Clin Endocrinol Metab 2013; 98: 4291-4299

[119] Salvi M, Vannucchi G, Currò N, Campi I, Covelli D, Dazzi D, Simonetta S, Guastella C, Pignataro L, Avignone S, Beck-Peccoz P. Efficacy of B-cell targeted therapy with rituximab in patients with active moderate to severe graves' orbitopathy: A randomized controlled study. J Clin Endocrinol Metab 2015; 100: 422-431

[120] Stan MN, Garrity JA, Carranza Leon BG, Prabin T, Bradley EA, Bahn RS. Randomized controlled trial of rituximab in patients with Graves' orbitopathy. J Clin Endocrinol Metab 2015; 100: 432-441

[121] Stan MN, Salvi M. Management of Endocrine Disease: Rituximab therapy for Graves' orbitopathy - lessons from randomized control trials. Eur J Endocrinol 2017; 176: R101-R109

[122] Perez-Moreiras JV, Alvarez-Lopez A, Gomez EC. Treatment of active corticosteroid-resistant graves' orbitopathy. Ophthal Plast Reconstr Surg 2014; 30: 162-167

[123] Smith TJ, Kahaly G], Ezra DG, Fleming JC, Dailey RA, Tang RA, Harris G], Antonelli A, Salvi M, Goldberg RA, Gigantelli JW, Couch SM, Shriver EM, Hayek BR, Hink EM, Woodward RM, Gabriel K, Magni G, Douglas RS. Teprotumumab for Thyroid-Associated Ophthalmopathy. N Eng J Med 2017; 376: 1748-1761

[124] Krieger CC, Place RF, Bevilacqua C, Marcus-Samuels B, Abel BS, Skarulis MC, Kahaly G], Neumann S, Gershengorn MC. TSH/IGF-1 Receptor Cross Talk in Graves' Ophthalmopathy Pathogenesis. J Clin Endocrinol Metab 2016; 101: 2340-2347

[125] Minich WB, Dehina N, Welsink T, Schwiebert C, Morgenthaler NG, Köhrle J, Eckstein A, Schomburg L. Autoantibodies to the IGF1 Receptor in Graves' Orbitopathy. J Clin Endocrinol Metab 2013; 98 : 752-760

[126] Chen H, Mester T, Raychaudhuri N, Kauh CY, Gupta S, Smith T], Douglas RS. Teprotumumab, an IGF-1R blocking monoclonal antibody inhibits TSH and IGF-1 action in fibrocytes. J Clin Endocrinol Metab 2014; 99: E1635-E1640

[127] Wu CY, Niziol LM, Musch DC, Kahana A. Thyroid-Related Orbital Decompression Surgery: A Multivariate Analysis of Risk Factors and Outcomes. Ophthal Plast Reconstr Surg 2017; 33: 189-195

[128] Baschieri L, Antonelli A, Nardi S, Alberti B, Lepri A, Canapicchi R, Fallahi P. Intravenous immunoglobulin versus corticosteroid in treatment of Graves' ophthalmopathy. Thyroid 1997; 7: 579-585

[129] Kahaly G, Pitz S, Muller-Forell W, Hommel G. Randomized trial of intravenous immunoglobulins versus prednisolone in Graves' ophthalmopathy. Clin Exp Immunol 1996; 106: 197-202

[130] Paridaens D, van den Bosch WA, van der Loos TL, Krenning EP, van Hagen PM. The effect of etanercept on Graves' ophthalmopathy: A pilot study. Eye (Lond) 2005; 19: 1286-1289

[131] Ayabe R, Rootman DB, Hwang C], Ben-Artzi A, Goldberg R. Adalimumab as steroid-sparing treatment of inflammatory-stage thyroid eye disease. Ophthal Plast Reconstr Surg 2014; 30: 415-419

[132] Ye X, Bo X, Hu X, Cui H, Lu B, Shao J, Wang J. Efficacy and safety of mycophenolate mofetil in patients with active moderate-to-severe Graves' orbitopathy. Clin Endocrinol (Oxf) 2017; 86: 247-255

[133] Kahaly G], Riedl M, Konig J, Pitz S, Ponto K, Diana T, Kampmann E, Kolbe E, Eckstein A, Moeller LC, Fuhrer D, Salvi M, Curro N, Campi I, Covelli D, Leo M, Marino M, Menconi F, Marcocci C, Bartalena L, Perros P, Wiersinga WM. Mycophenolate plus methylprednisolone versus methylprednisolone alone in active, moderate-to-severe 
Graves' orbitopathy (MINGO): a randomised, observer-masked, multicentre trial. Lancet Diabetes Endocrinol 2018; 6: 287-298

[134] Liu ZW, Masterson L, Fish B, Jani P, Chatterjee K. Thyroid surgery for Graves' disease and Graves' ophthalmopathy. Cochrane Database System Rev 2015; CD010576

[135] Marcocci C, Bruno-Bossio G, Manetti L, Tanda ML, Miccoli P, lacconi P, Bartolomei MP, Nardi M, Pinchera A, Bartalena L. The course of Graves' ophthalmopathy is not influenced by near total thyroidectomy: A case-control study. Clin Endocrinol (Oxf) 1999; 51: 503-508

[136] Meyer zu Horste M, Pateronis K, Walz MK, Alesina P, Mann K, Schott M, Esser J, Eckstein AK. The Effect of Early Thyroidectomy on the Course of Active Graves' Orbitopathy (GO): A Retrospective Case Study. Horm Metab Res 2016; 48: 433-439

[137] Leo M, Marcocci C, Pinchera A, Nardi M, Megna L, Rocchi R, Latrofa F, Altea MA, Mazzi B, Sisti E, Profilo MA, Marino M. Outcome of Graves' orbitopathy after total thyroid ablation and glucocorticoid treatment: Follow-up of a randomized clinical trial. J Clin Endocrinol Metab 2012; 97: E44-E48
[138] Durrani OM, Reuser TQ, Murray PI. Infliximab: a novel treatment for sight-threatening thyroid associated ophthalmopathy. Orbit 2005; 24: $117-119$

[139] Pascual-Camps I, Molina-Pallete R, Bort-Marti MA, Todoli ], Espana-Gregori E. Tocilizumab as first treatment option in optic neuropathy secondary to Graves' orbitopathy. Orbit 2018; 1-4. doi:10.1080/01676830.2018.1435694 [Epub ahead of print]

[140] Liu C, Dalm V, van Hagen PM, Croon-de Boer F, Paridaens D. Chemotherapy-induced exacerbations of thyroid orbitopathy in a patient with B-cell lymphoma. Orbit 2018; 37: 299-302

[141] Krassas GE, Stafilidou A, Boboridis KG. Failure of rituximab treatment in a case of severe thyroid ophthalmopathy unresponsive to steroids. Clin Endocrinol (Oxf) 2010; 72: 853-855 